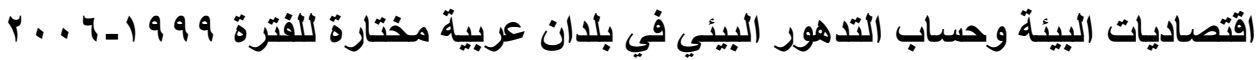

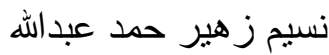

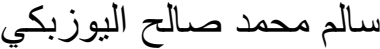

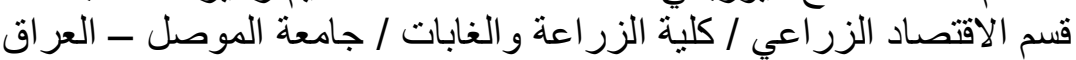 Naseem.zuhair@yahoo.co salim51956@yahoo.com
}

\section{الخلاصة التانة}

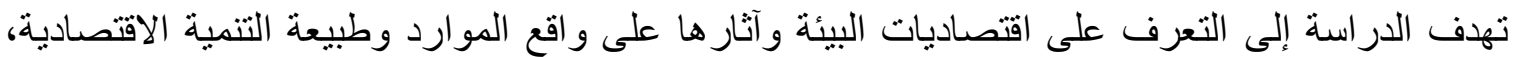

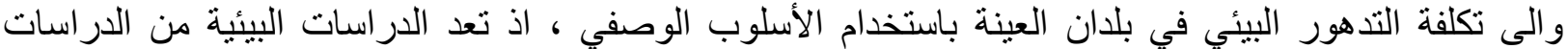
الحديثة ، حيث اخذت تحتل مكان الصدارة في العصر الحالي ، وذلك بسبب ما تعانيه البيئة اليوم من مشكلات

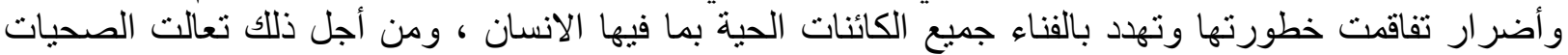

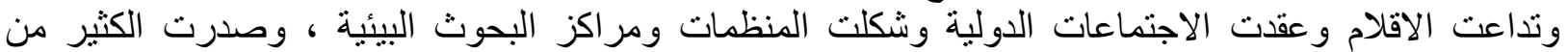
التشريعات ، لوضع حد لهذا التدهور البيئي، المنذر بالأخطار المتوقعة للأرض و المهددة بالفناء لكل الكائنات التئ الحية

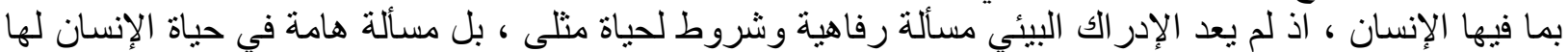

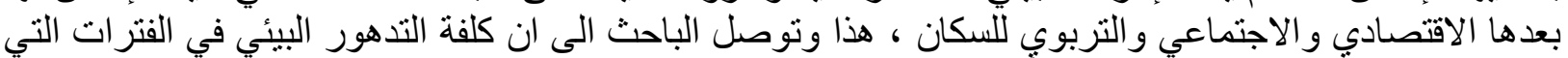

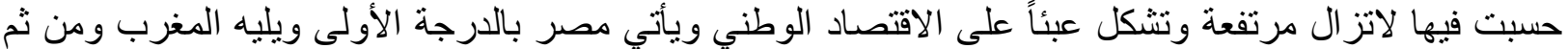
سوريا و الأردن على التو الي وهذا يعني ضياع مردودات وعو ائد اجتماعية وبيئية وصحية و اقتصادية مختلفة كانت

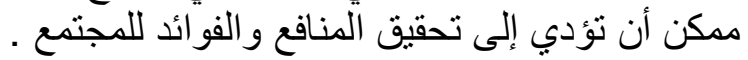

\section{المقدمة}

لم تعد البيئة في مائها أو هو ائها أو تربتها أو مواردها أو أحزمتها الخضر اء معطى مجانياً يمكن التعامل معه التها

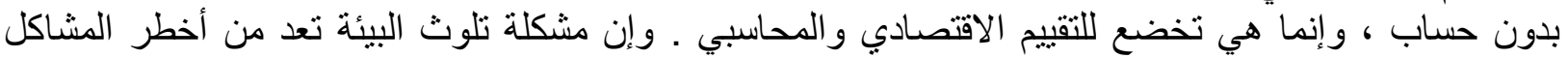

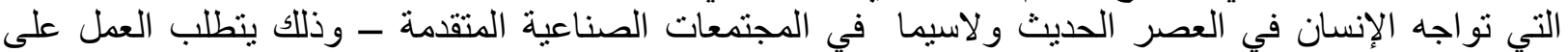

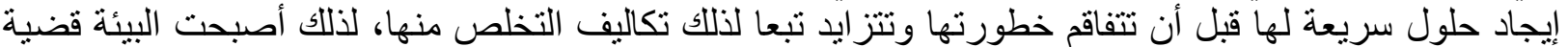
أساسية ليست فقط لاعتبار ات بيئية، و إنما لاعتبار ات سياسية و اقتصادية واجتماعية، وأصبح التفكير الأكثر جدية

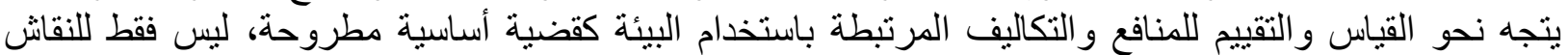

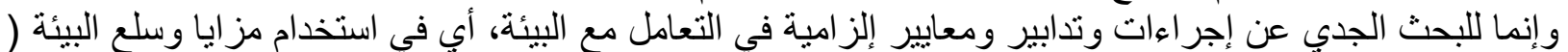

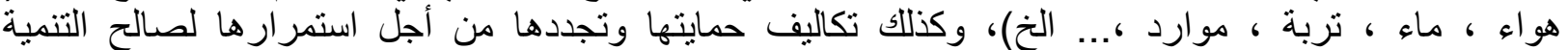

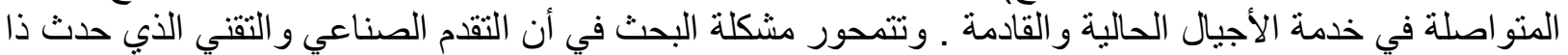

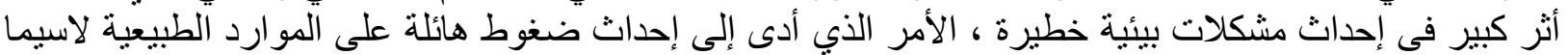

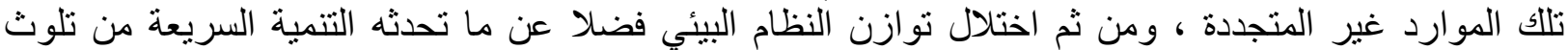

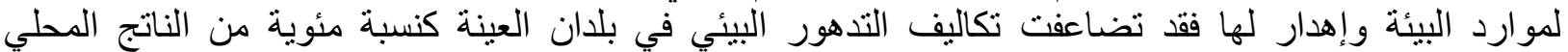
الإجمالي ، لذا تتأتى أهمية البحث من تنوع وتتداخل المشاكل البيئية من حيث أسبابها ونتائجها ، إذ تزايدة اليدات الأهمية

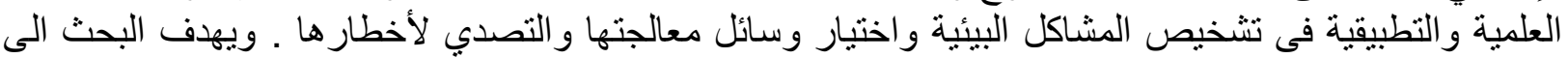

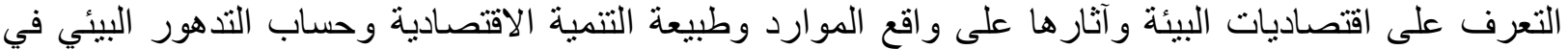

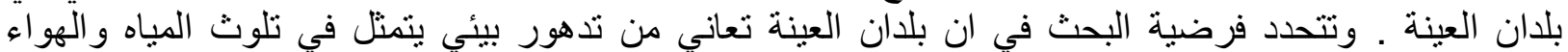

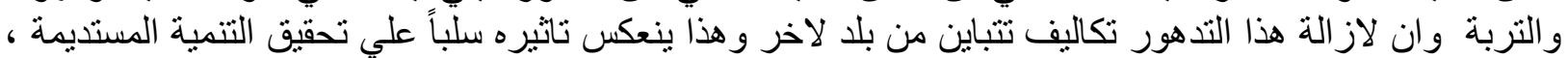

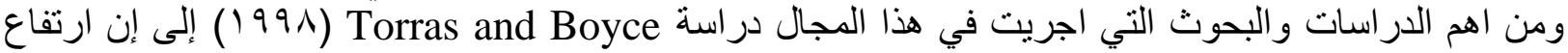

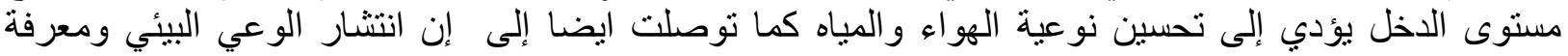

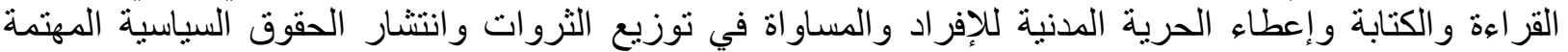

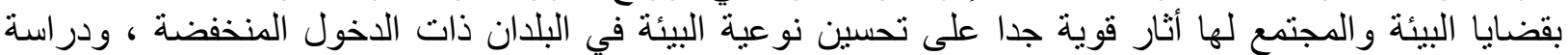

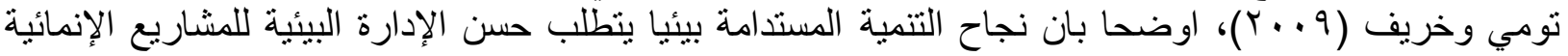

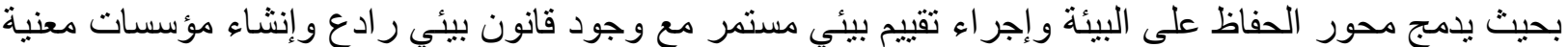

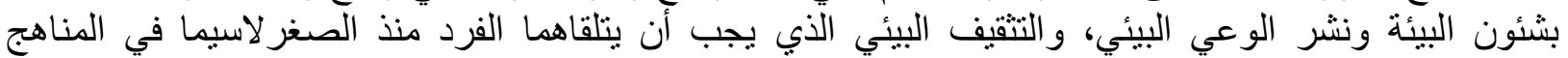

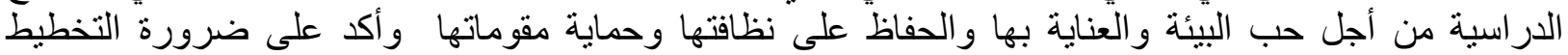

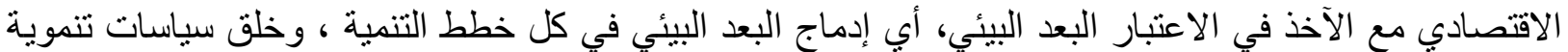

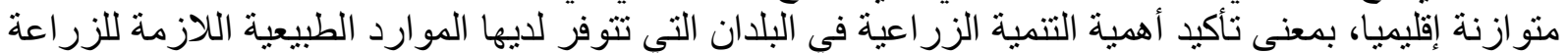


و التركيز على التنمية الصناعية بهدف تطوير الاقتصاد ، ويجب وجود إدارة مركزية مسؤولة وفعالة تستطيع تجميع

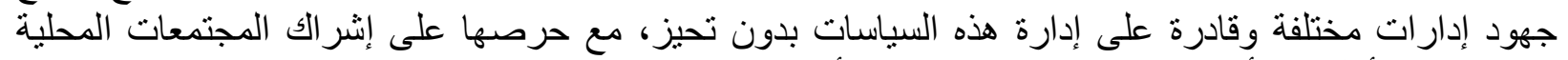

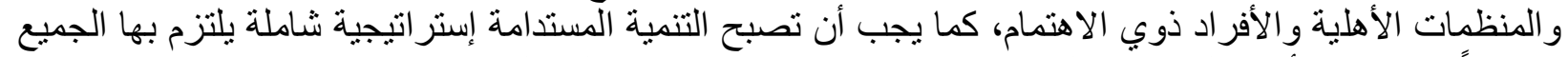

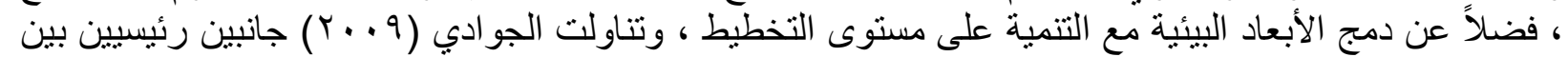

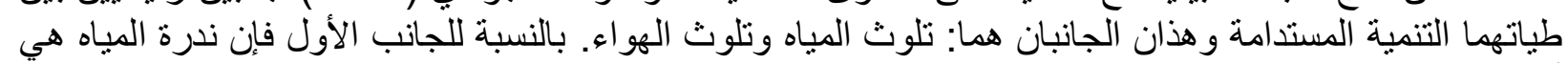

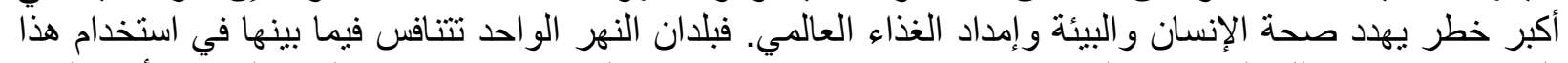

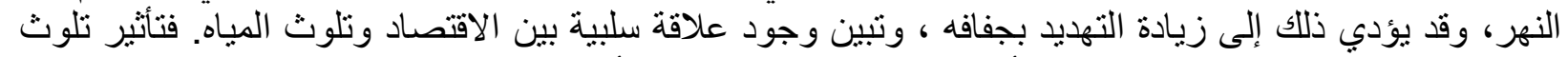

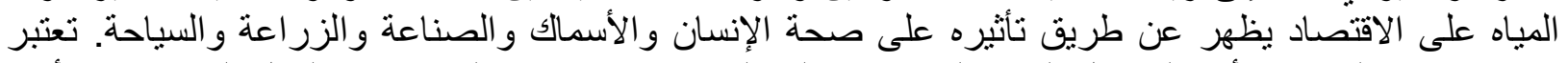

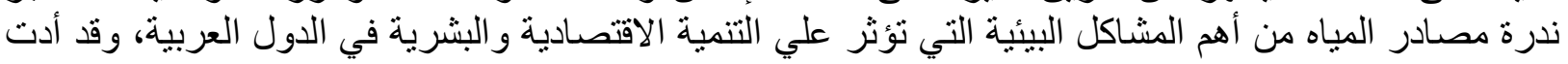

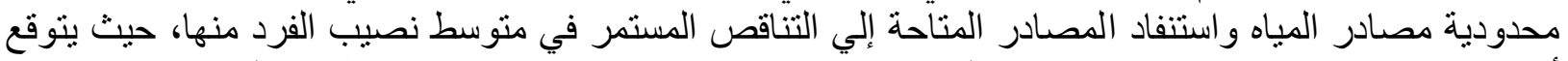

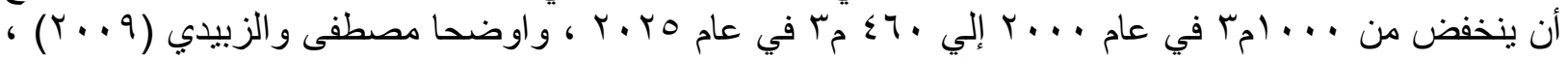

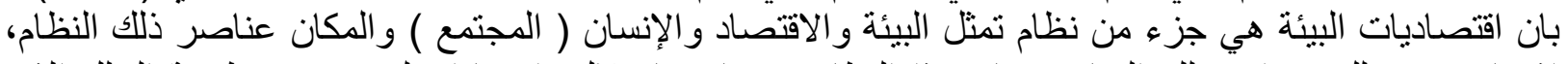

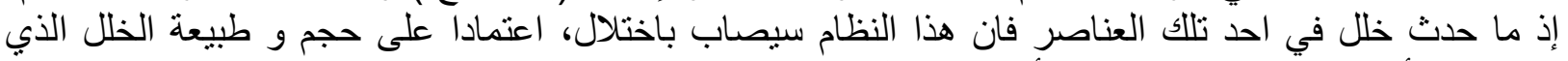

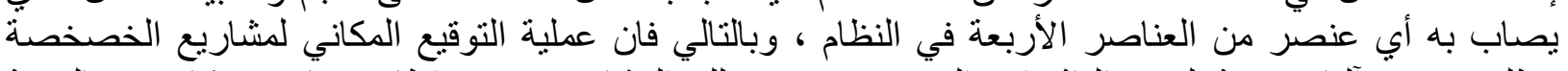

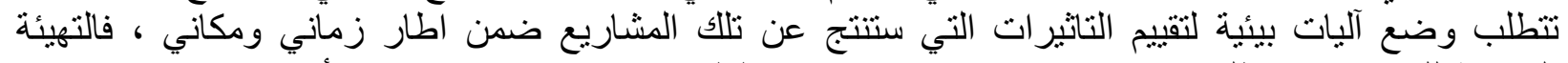

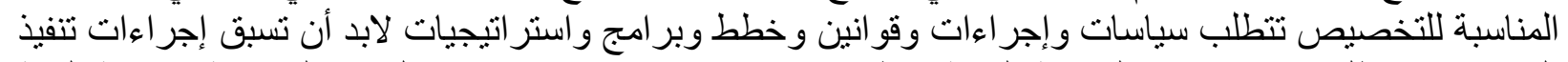

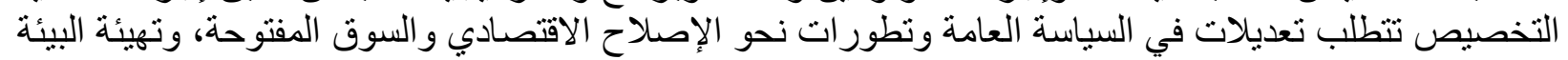

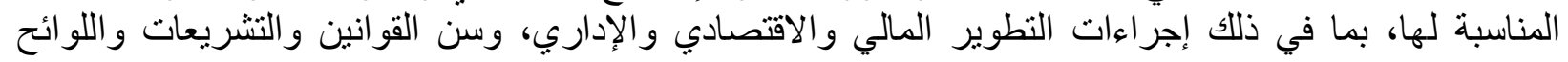

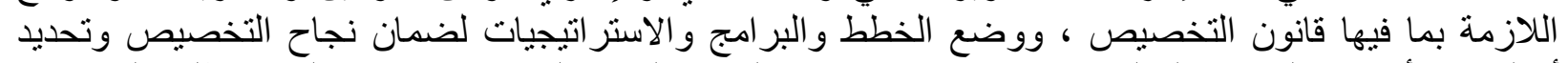

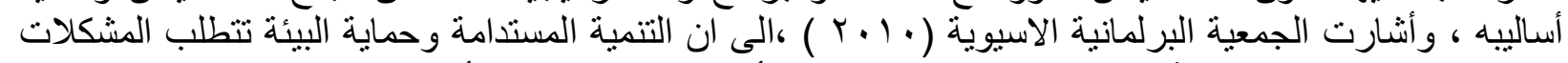

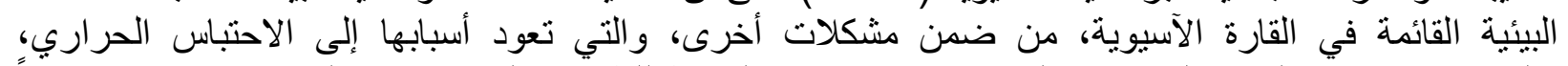

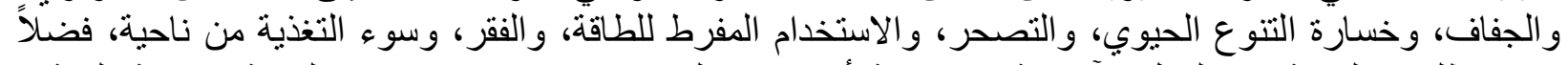

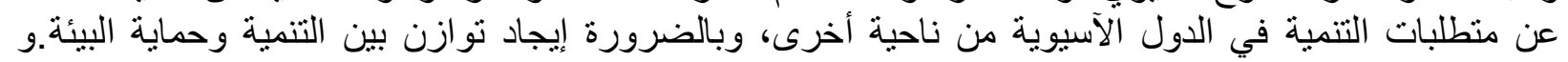

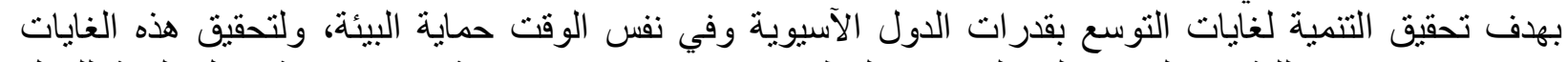

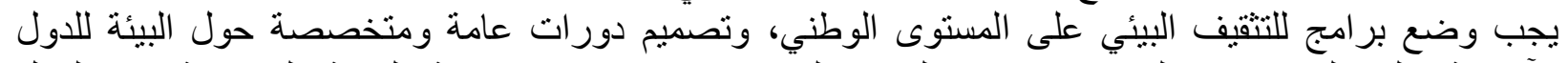

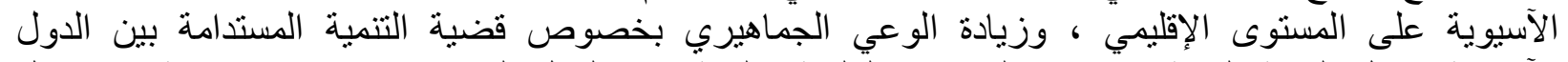

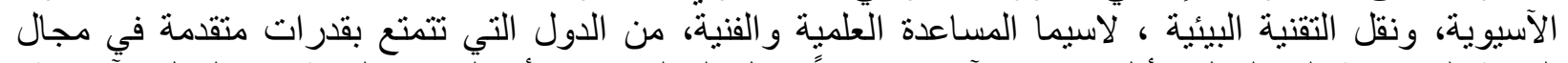

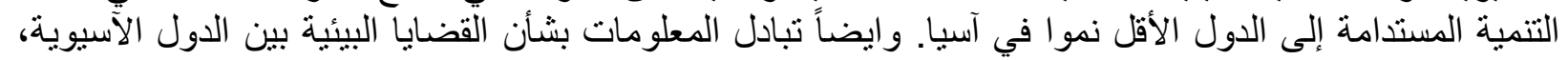

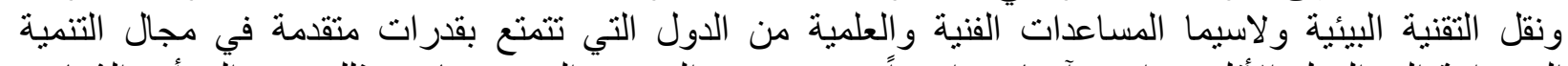

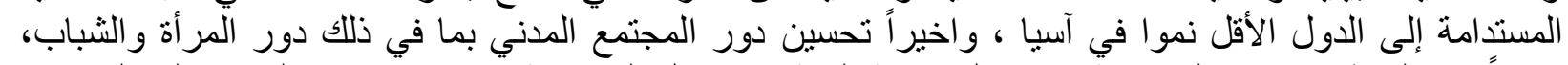

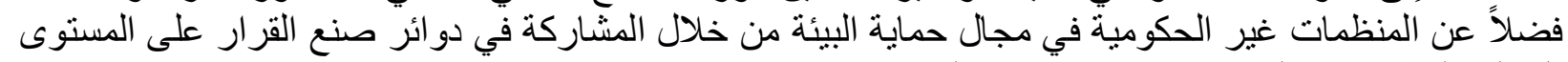

\section{مواد البحث وطر ائقه}

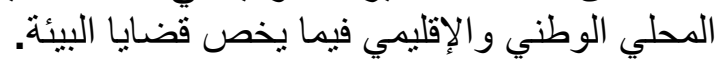

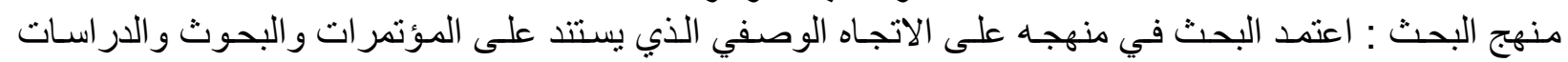

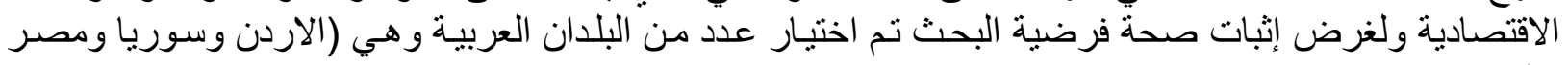
و المغرب)

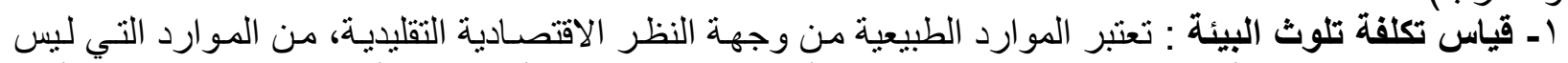

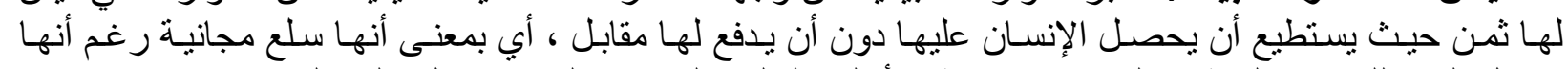

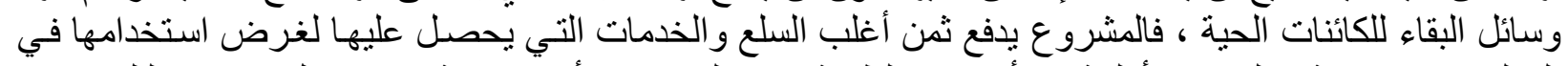

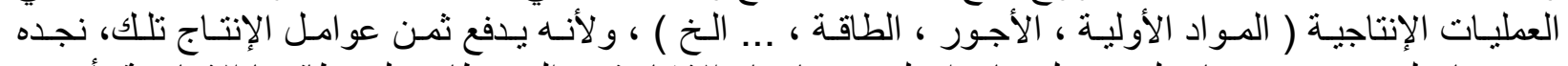

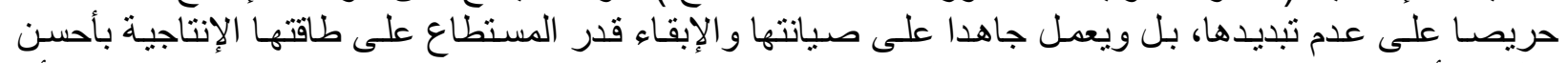

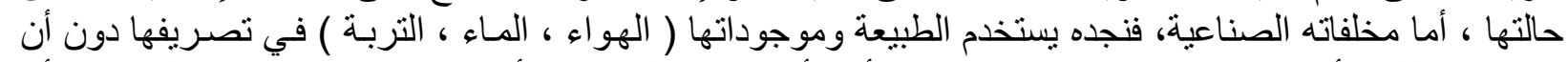

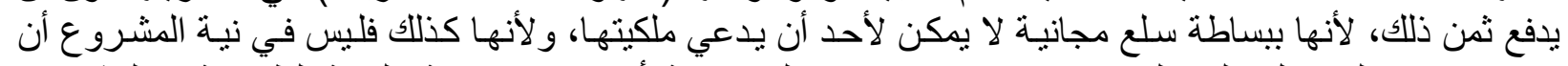

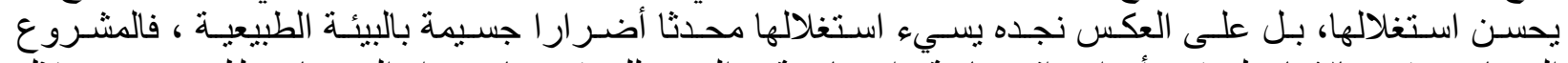

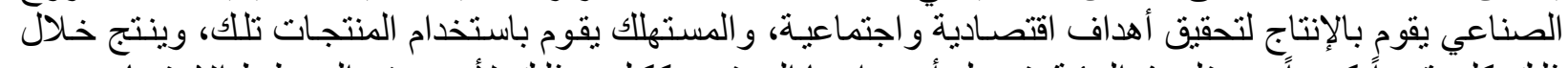

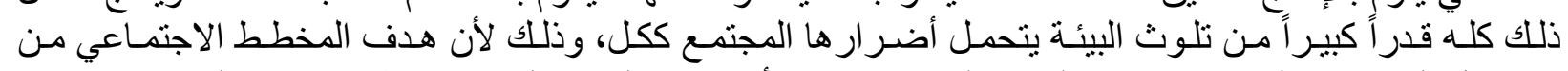

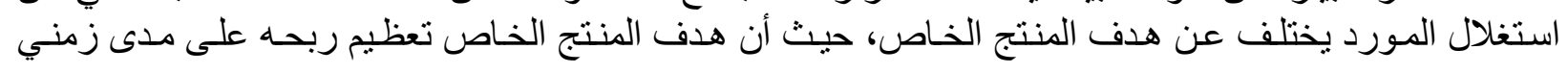




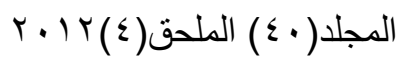
ISSN:2224-9796(Online)
ISSN: 1815-316X(Print)
مجلة زر اعة الر افدين

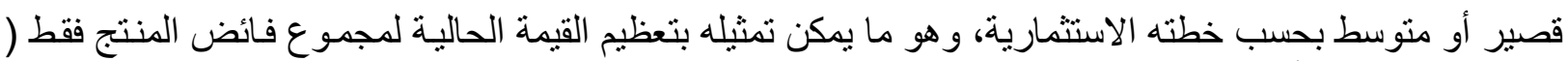

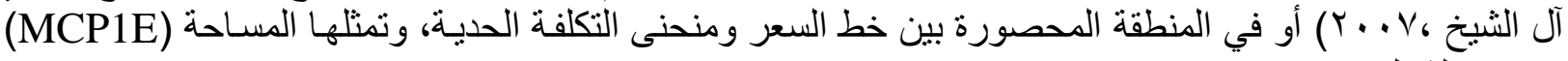

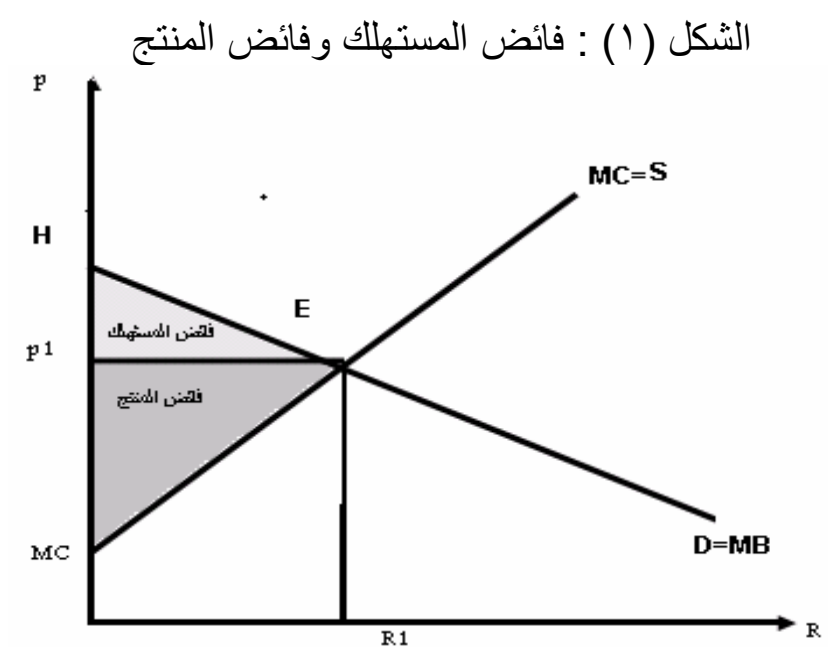

كما في الثكل الاتي :

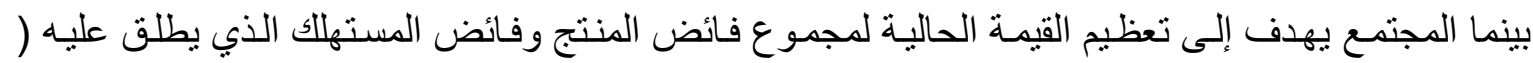

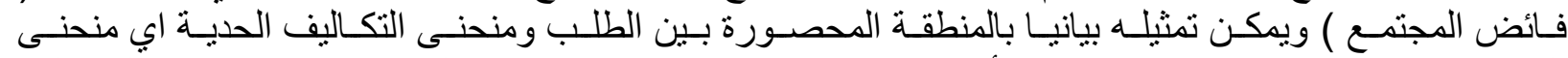

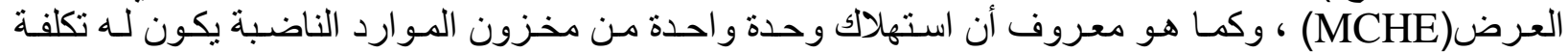

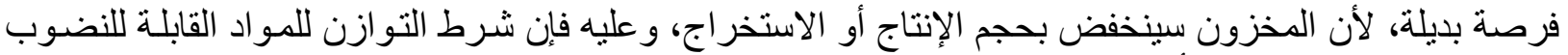

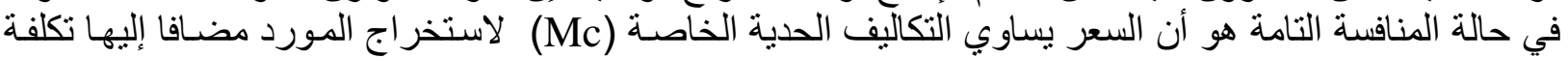

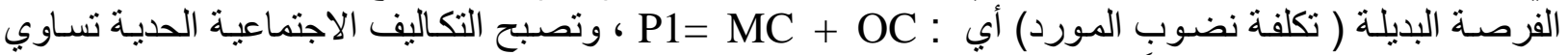
$\mathrm{MSC}=\mathrm{MC}+\mathrm{OC}$ التكاليف الحدية الخاصة مضافاً إليها تكاليف الفردة الفرة البديلة حيث : حيث Mc ت تكلفة الفرصة البديلة . OC MSC وبذلك يصبح الثكل البياني رقم (Y) لمجموع فائض المنتج و المستهلك في حالة وجود تكاليف فرصسة بديلة

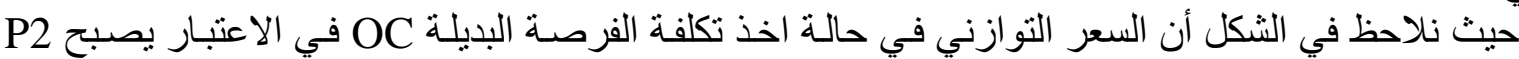
كما يأني :

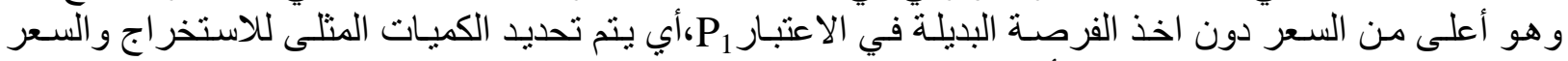

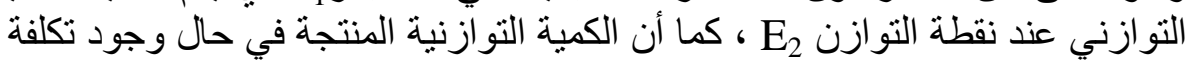

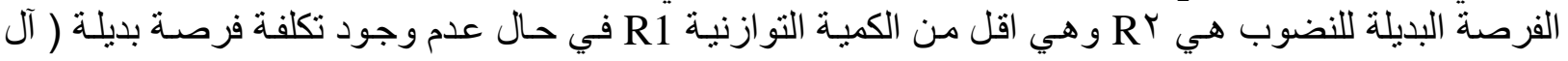

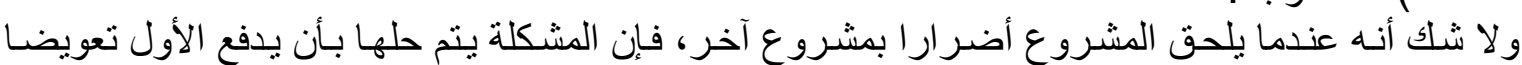

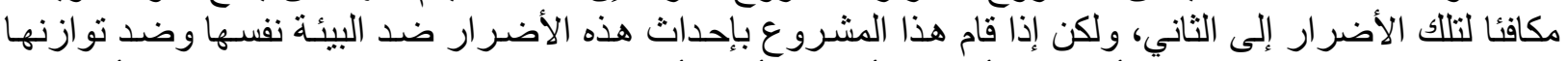

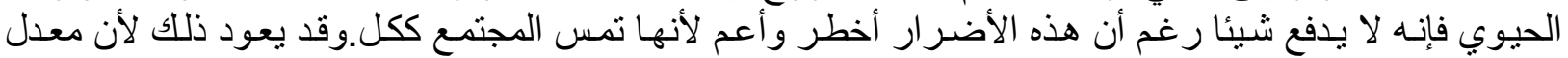

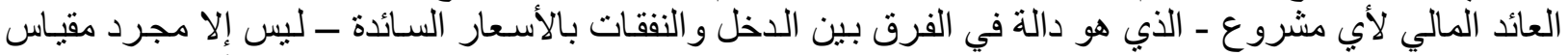

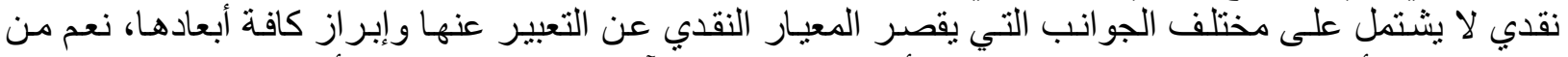

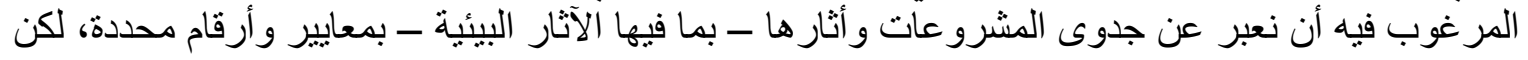

الثكل (r) : مجموع فائض المنتج و المستهلك في حالة وجود تكاليف فرصة بديلة 


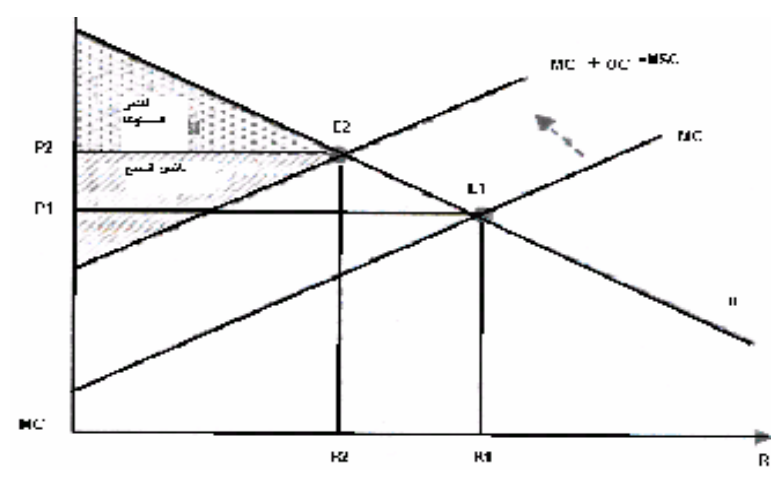

هذا الجانب رغم حجيته وبريقه لا يمكن أن يعبر بدقة عن كل المطلوب إبرازه، فمثلا يمكن حساب الزيادة في تكلفة الإنة

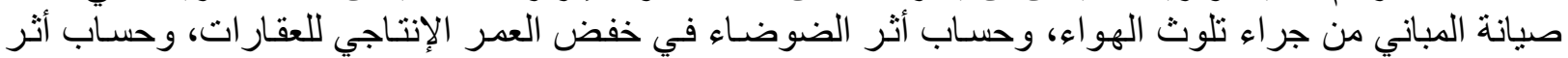

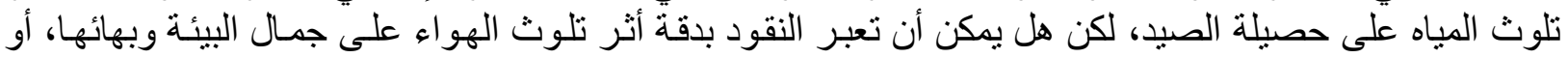

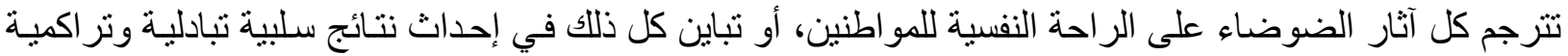

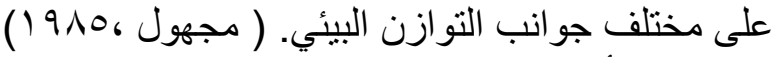

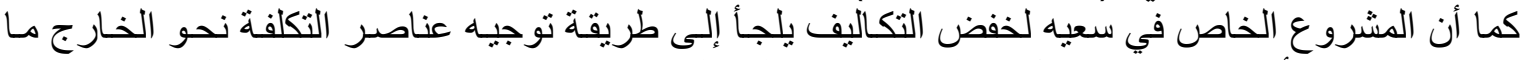

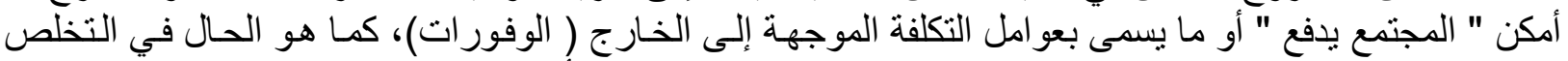

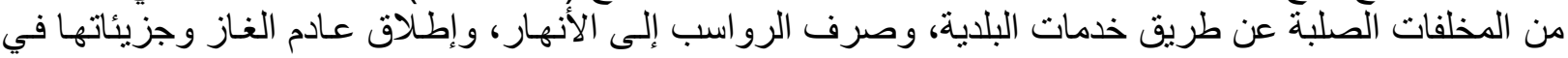

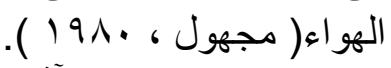

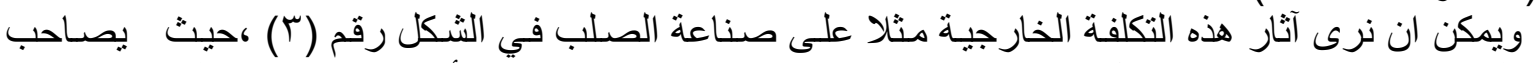

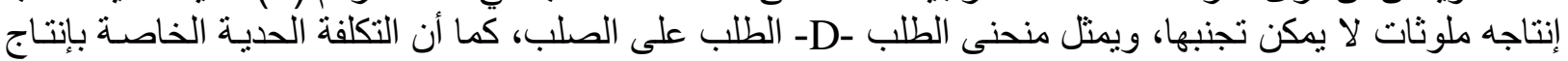

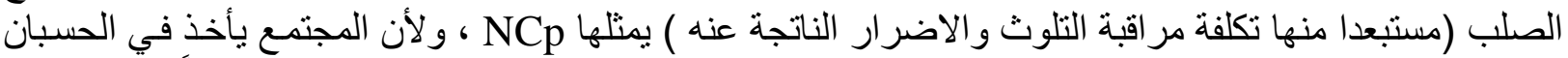

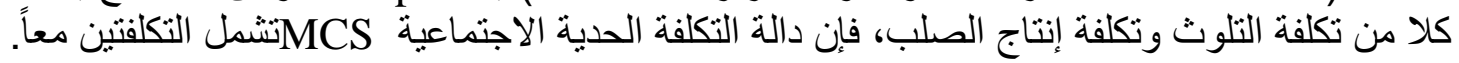

$$
\text { شكل (r) : توزيع السوق و علاقته بالتلوث }
$$

\section{توزيع ائسوف وتيالوقته باتتوثث}

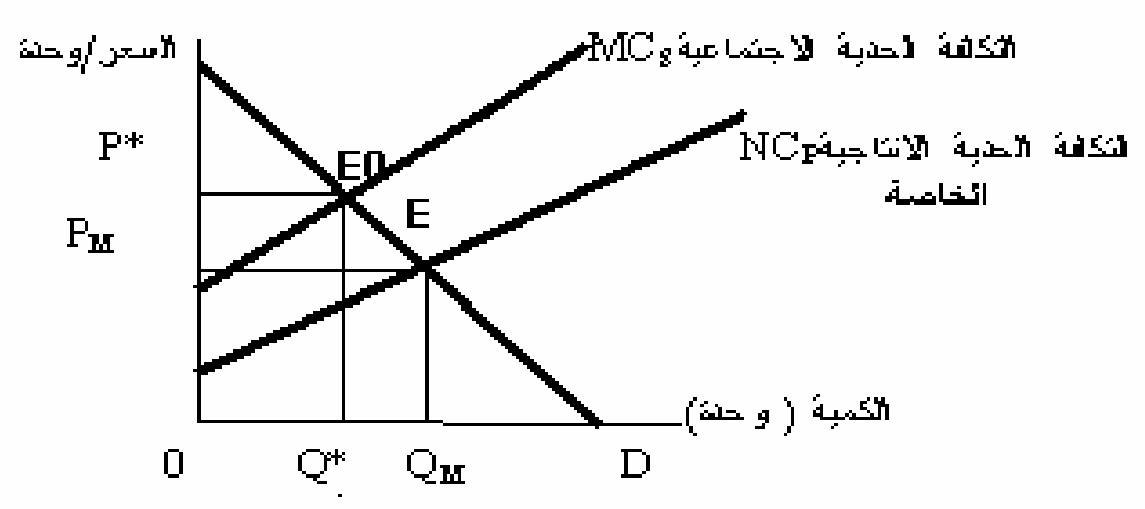

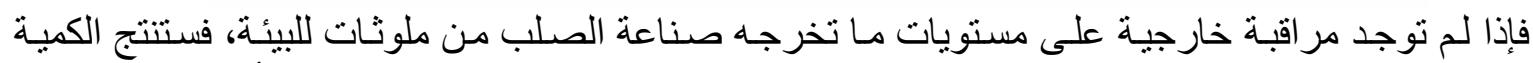

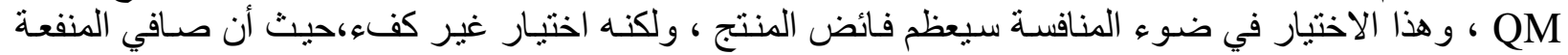

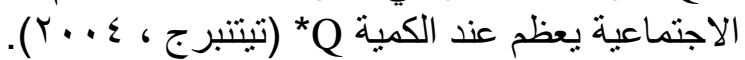

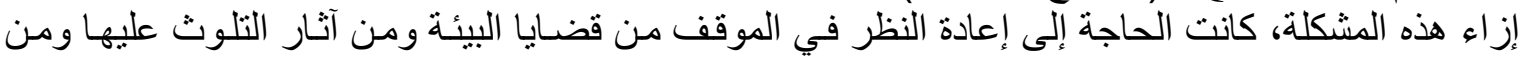

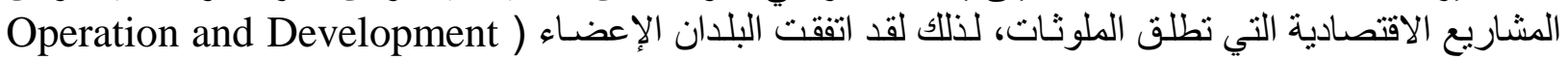
"Organization for Economic CO) "OECD

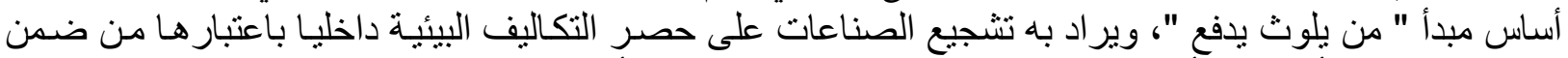

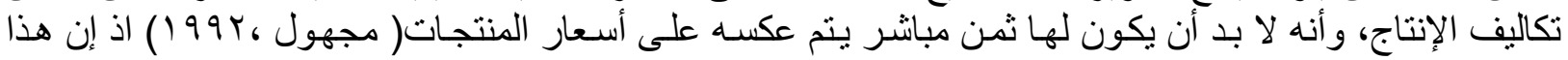

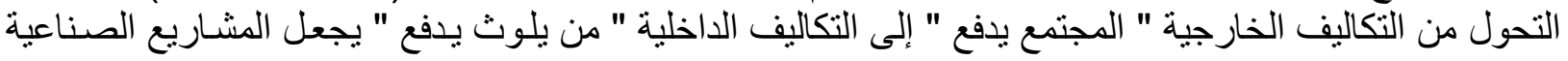


و الأطر اف الأخرى الملوثة هي التي تتحمل تكلفة تعويض المجتمع والبيئة نظير ما يتحمله من أضرار جراء التلوث

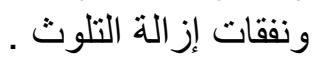

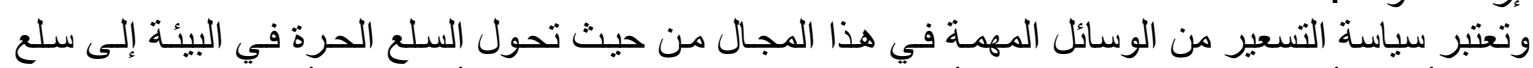

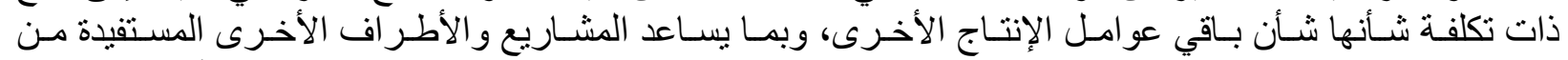

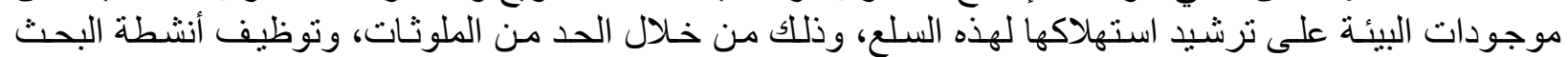

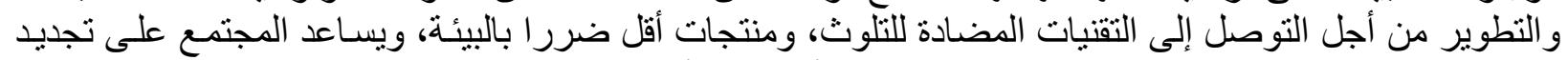

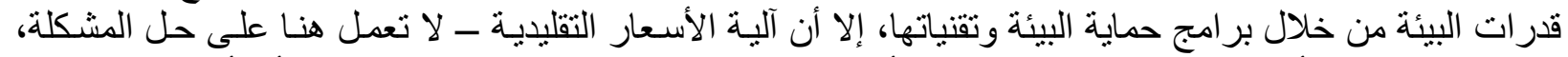

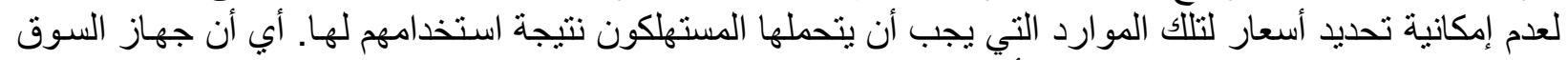

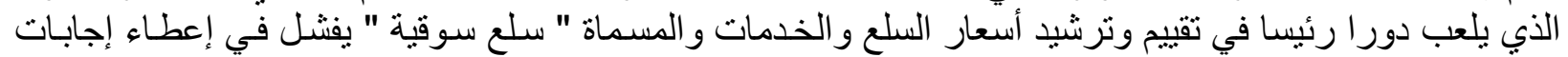

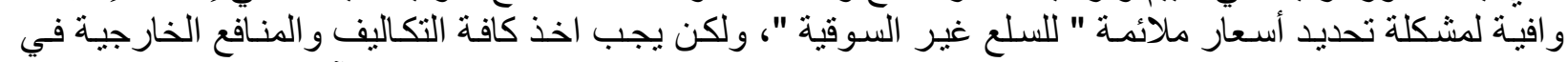

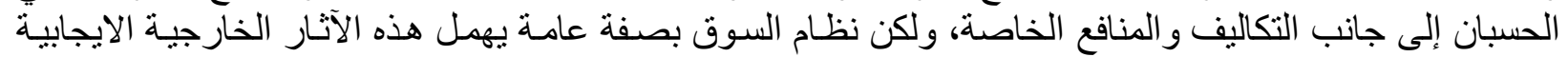

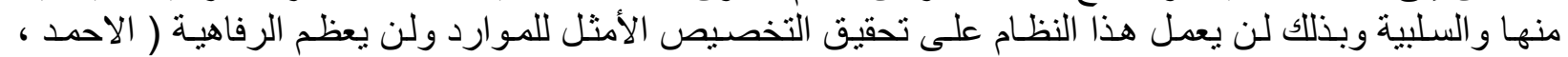
$(r . .9$ للذلك أصبح التفكير الأكثر جدية يتجه نحو القياس وتقييم التكاليف المرتبطة باستخدام البيئة وبر امج حمايتها

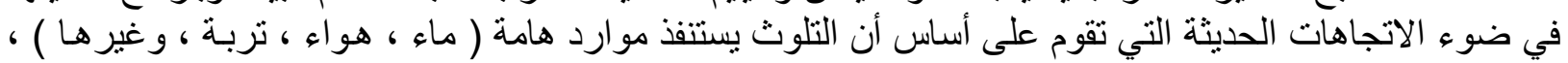

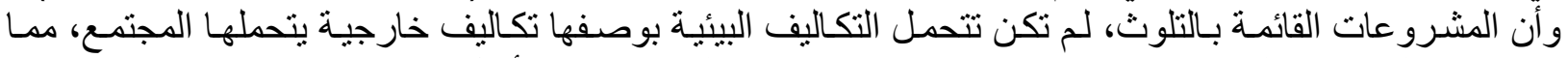

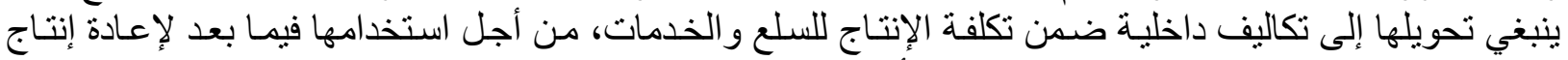

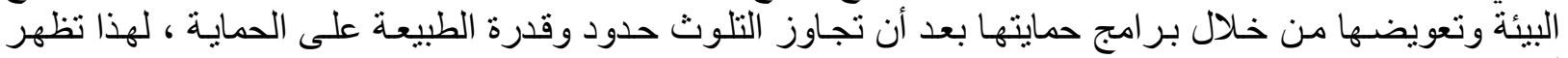

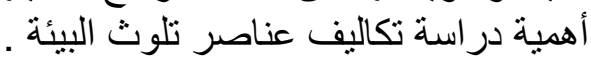

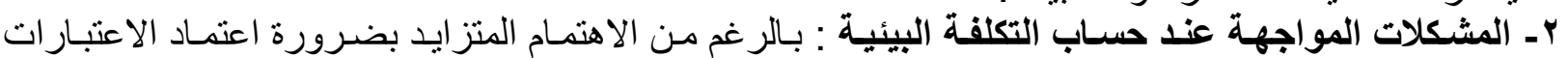

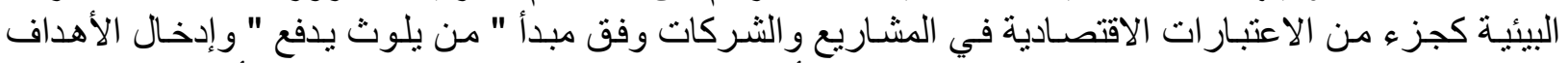
الجديدة في تطوير تكنولوجيات جديدة نظيفة ومنتجات أنظف ، أنسات ، فقد برزت مشكلات عديدة من أهمها ( إبر اهيم ، $-:(r+. r$

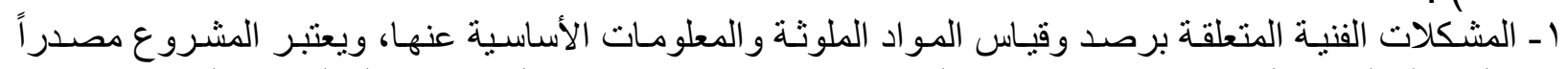

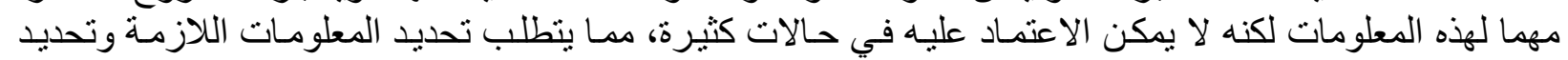

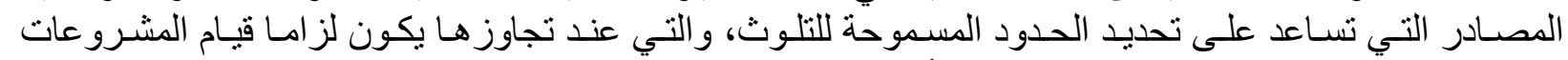

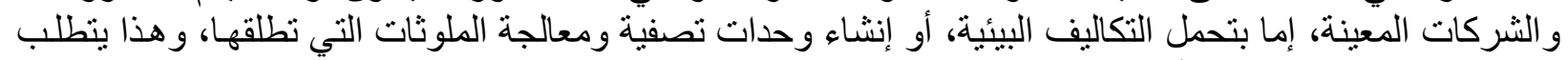

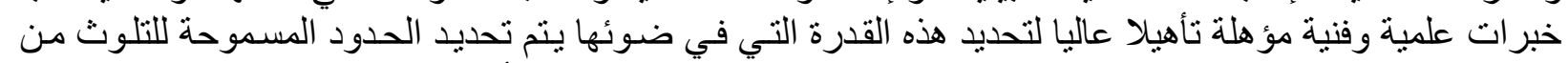

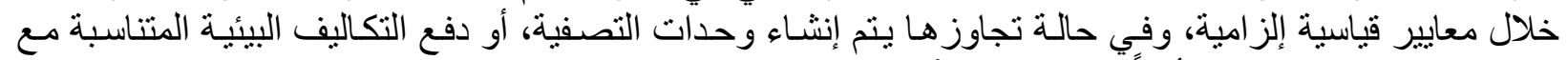

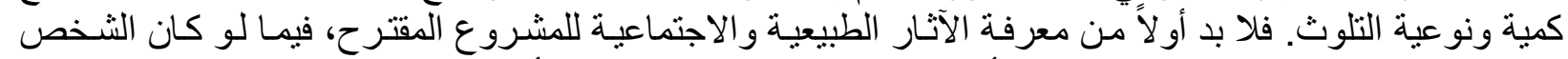

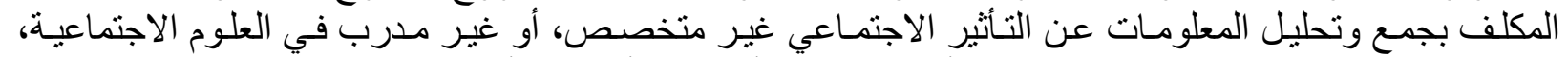

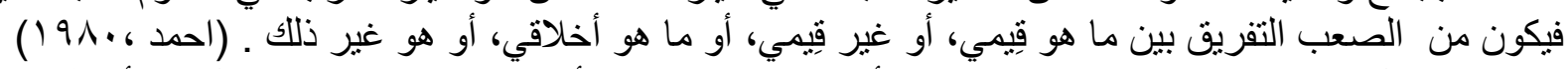

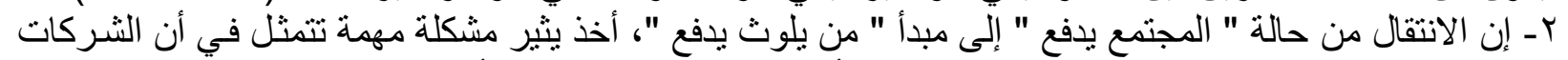

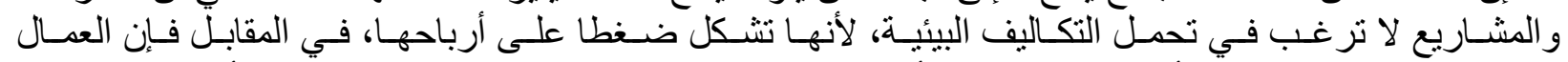

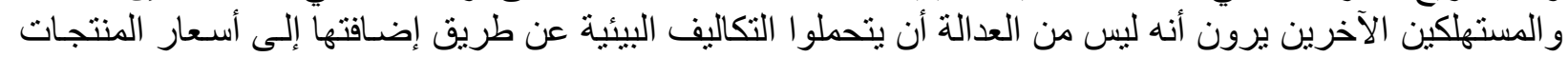

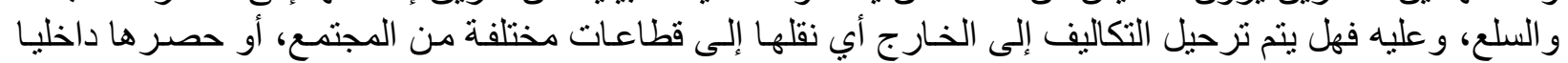

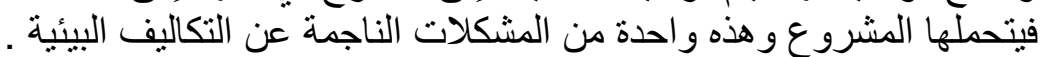

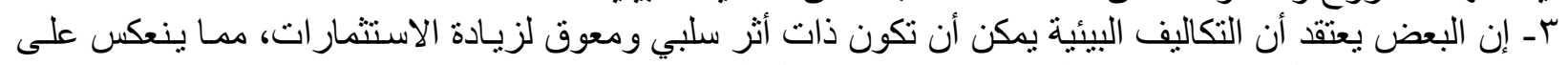

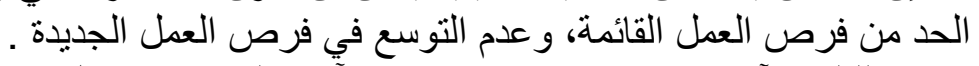

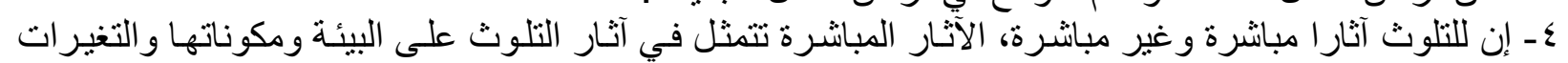

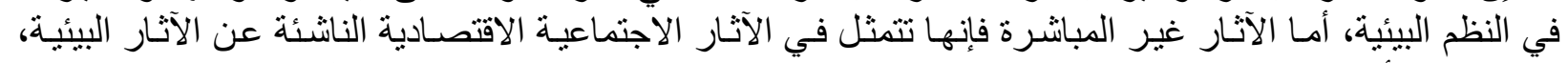

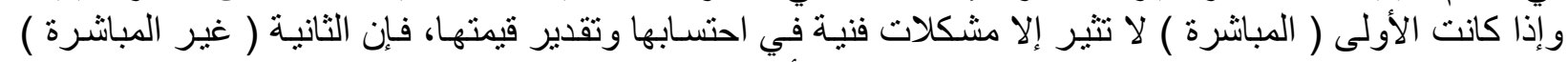

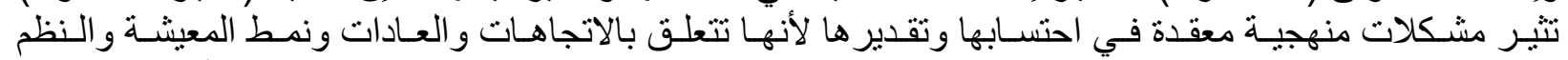

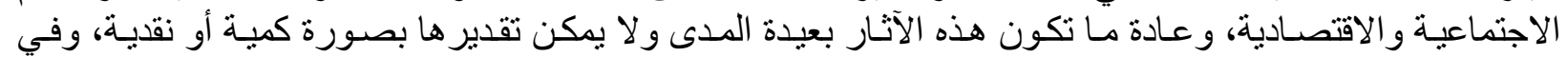

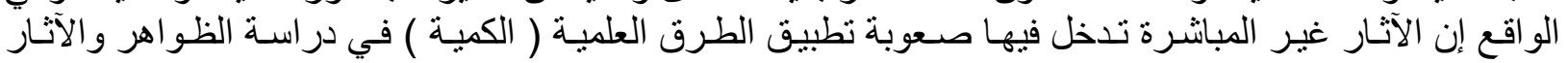

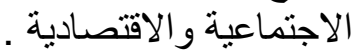




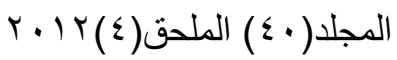
ISSN:2224-9796(Online)
ISSN: 1815-316X(Print)

مجلة زر اعة الر افدين

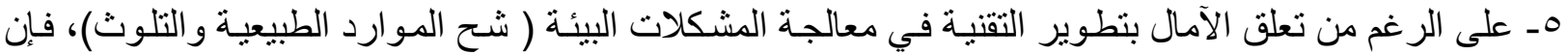

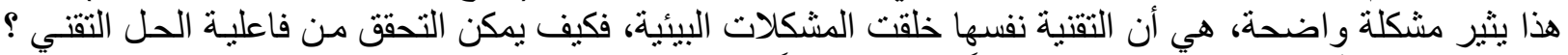

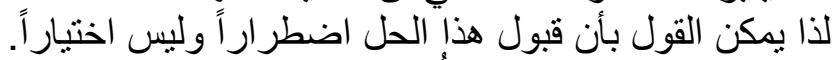

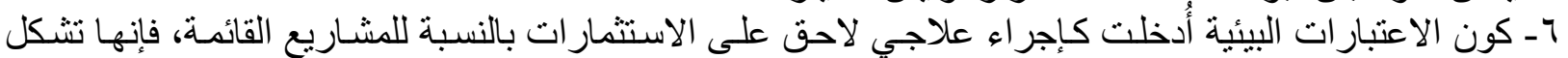

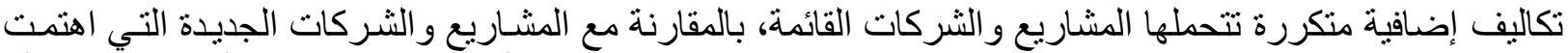

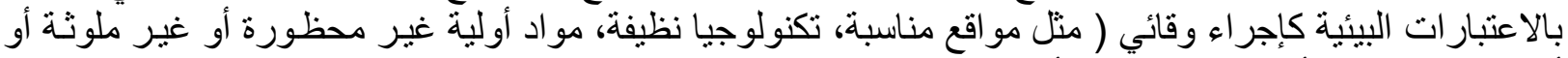

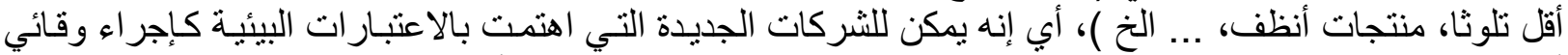

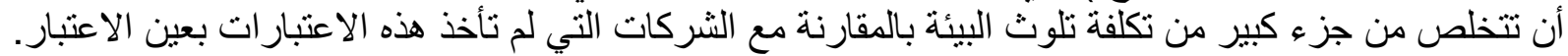

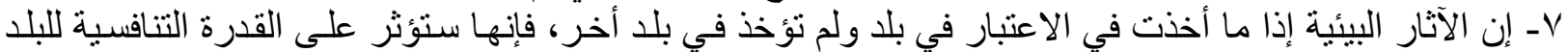

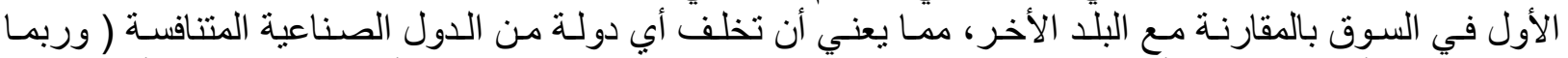

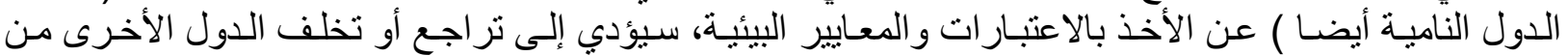

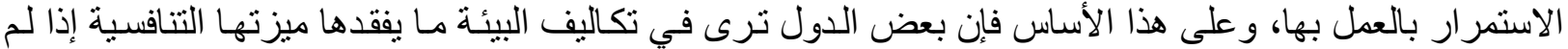

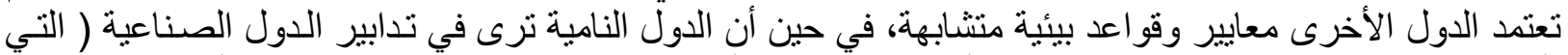

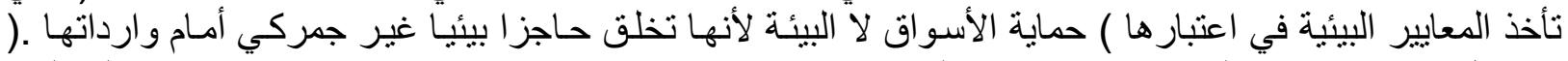

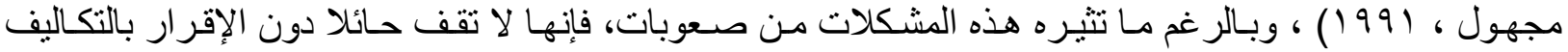

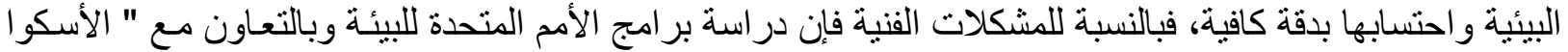

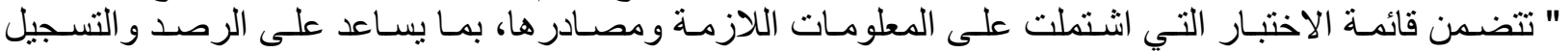

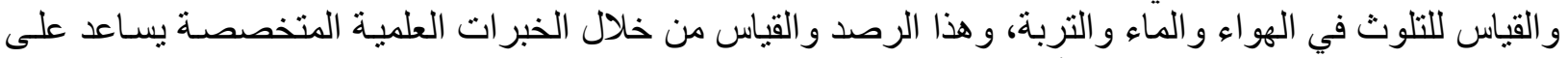

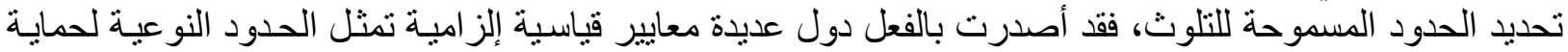

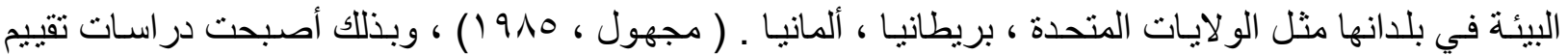

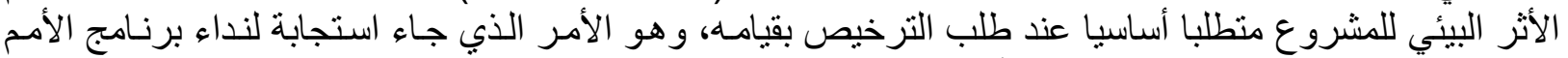

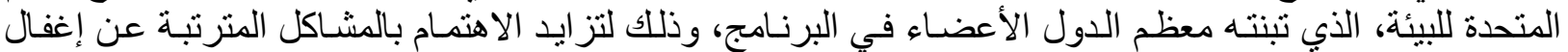

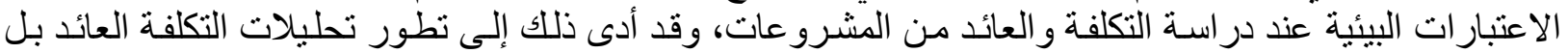

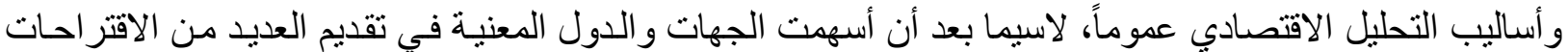

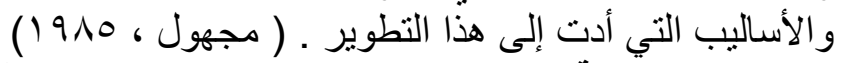

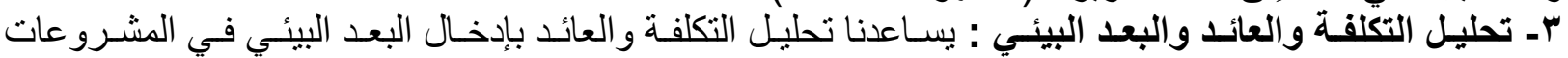

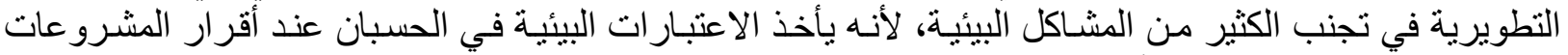

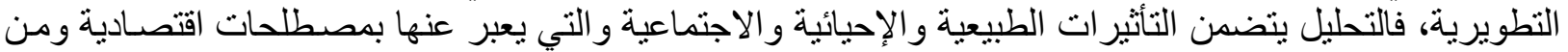

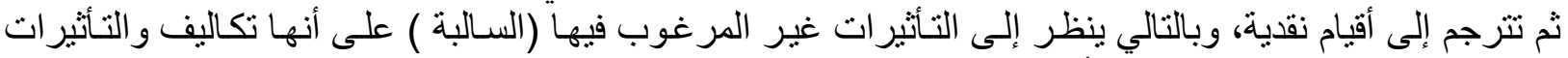

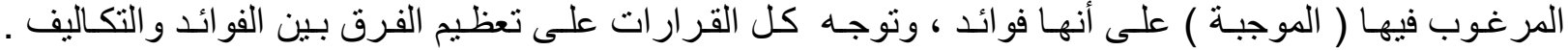

( $191 \wedge ،$ BOER و JAMES )

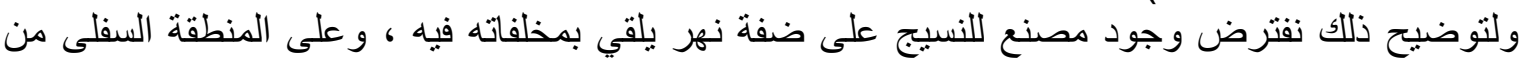

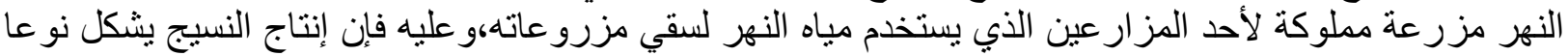

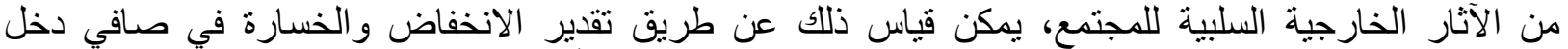

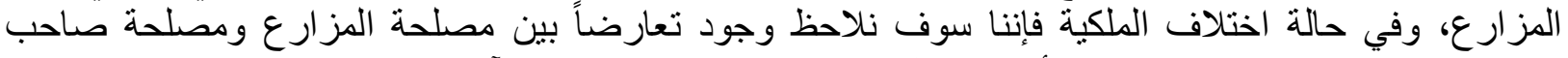

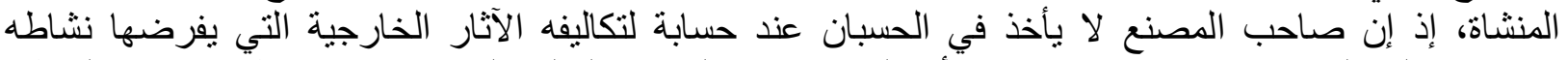

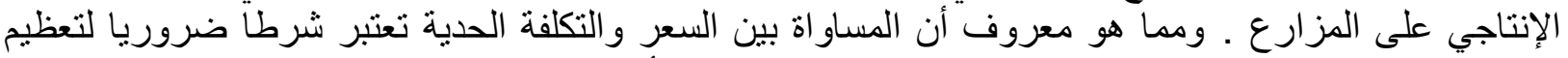

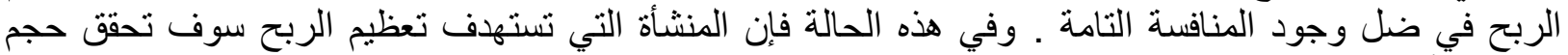

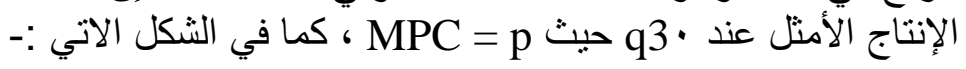




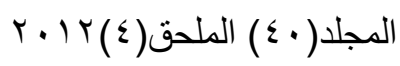
ISSN:2224-9796(Online)
ISSN: 1815-316X(Print)
مجلة زر اعة الر افدين

الشكل (ع) : توازن المنشأة حالة الاثار السلبية(سوق المنافسة التامة )

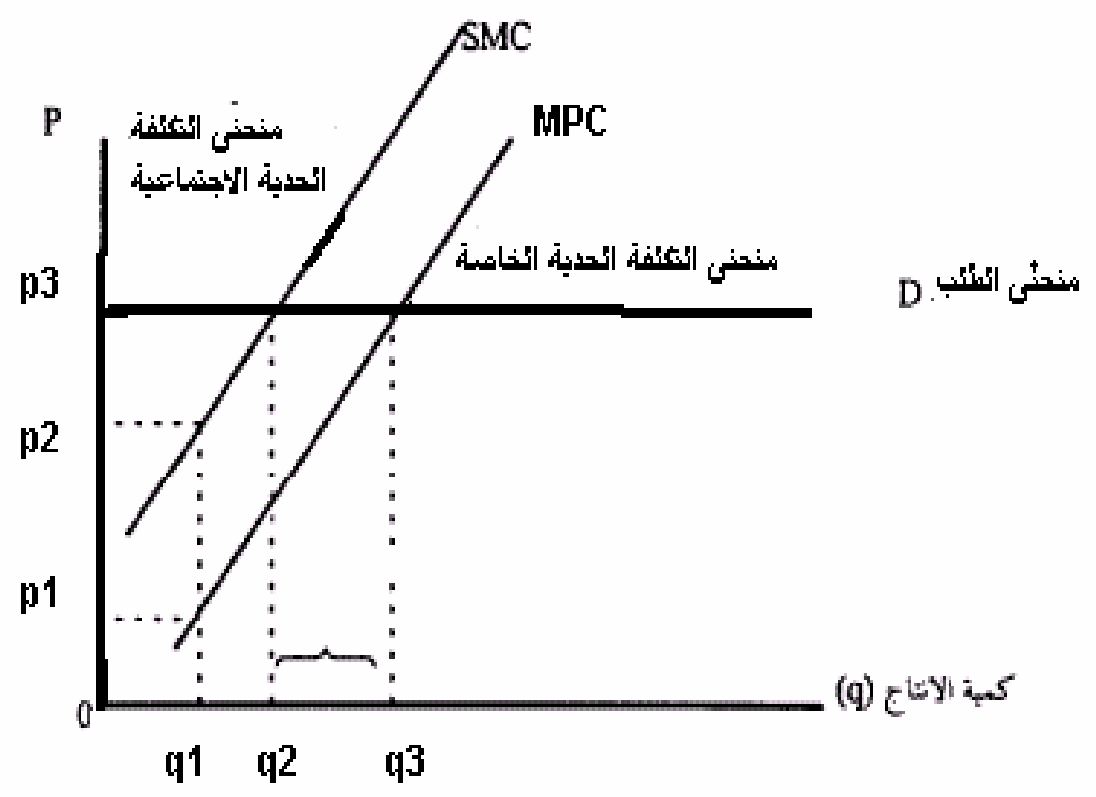

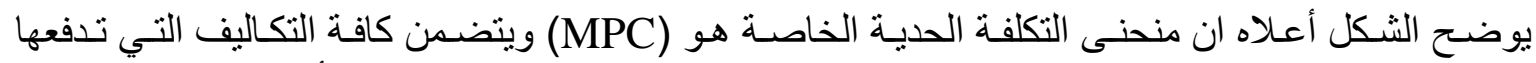

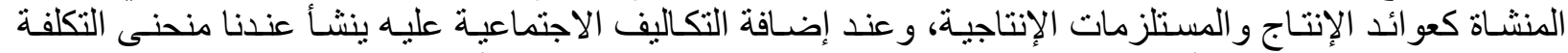

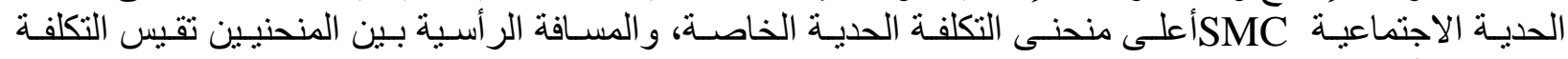

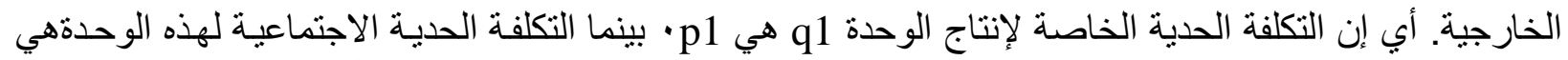

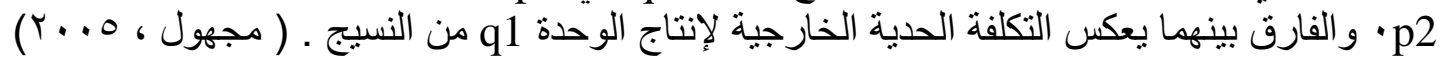

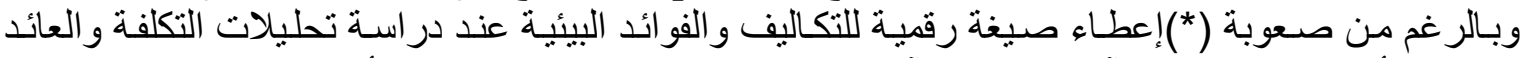

الاجتماعي ، إلا أنه يعد إلى دمج الآثار البيئية والآثار الخارجية مع التكاليف الخارجية الأخرى ،

(*) يمكن تطبيق ذلك عملياً على مستوى منتأت او وحدات صغيرة لاعلى مستوى بلد ككل.

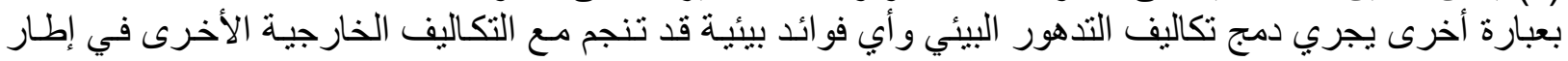

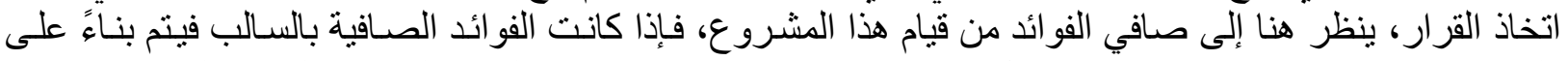

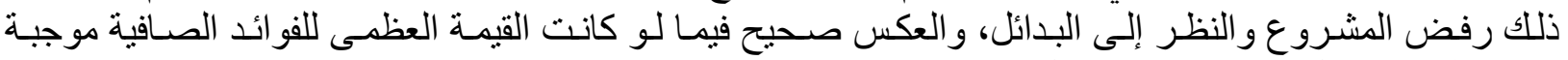

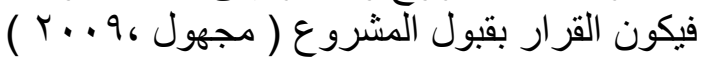

ع ـ التوجهات والسباسات الوضعية المتبعة لحماية البيئة وتحقيق التتمية المستديمة.

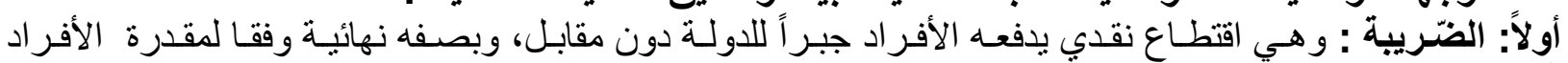

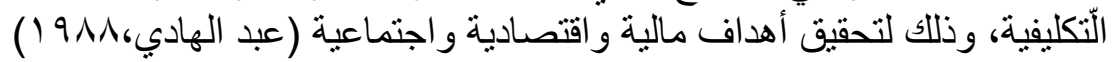

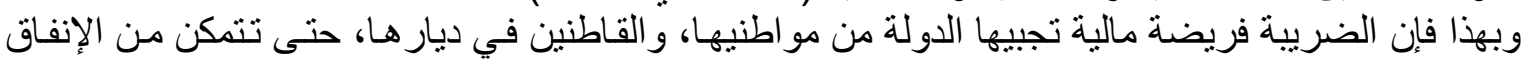

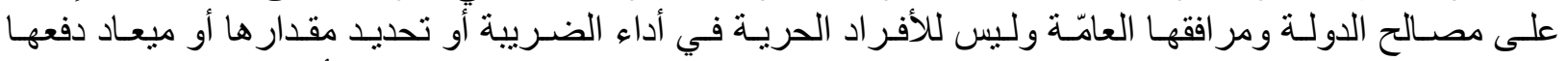

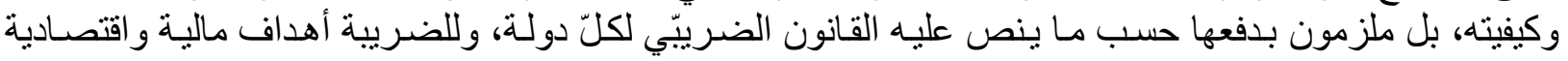

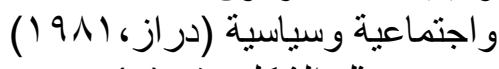

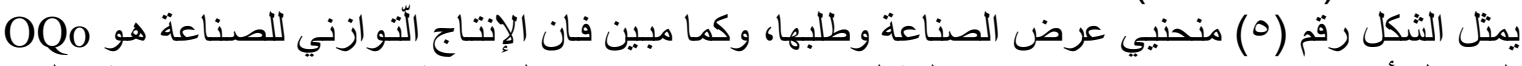

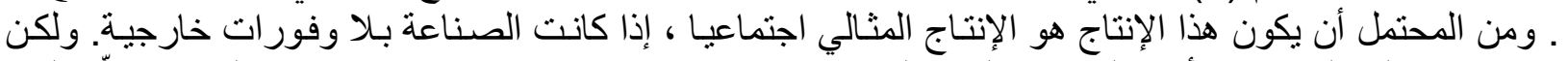

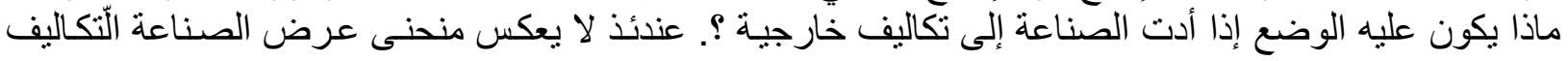

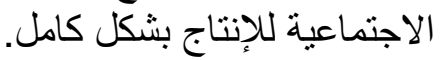




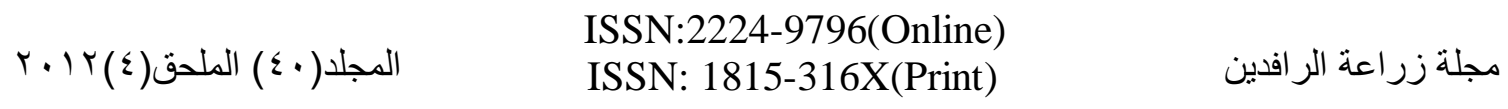

الثكل (0) : الإنتاج التوازني للصناعة في حال عدم وجود نفقات ووفورات خارجية

اتسبر

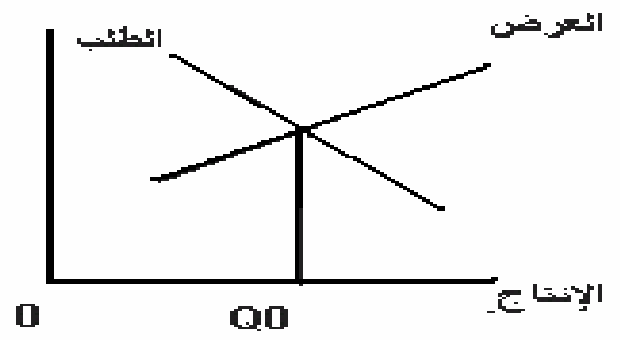

ويوضح الثكل (†) منحنى العرض الذي يعكس هذه التّكاليف الاجتماعية هو S1 و الذي يقع الى يسـار منحنى

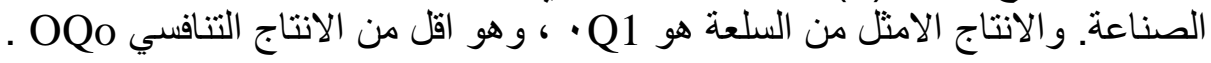

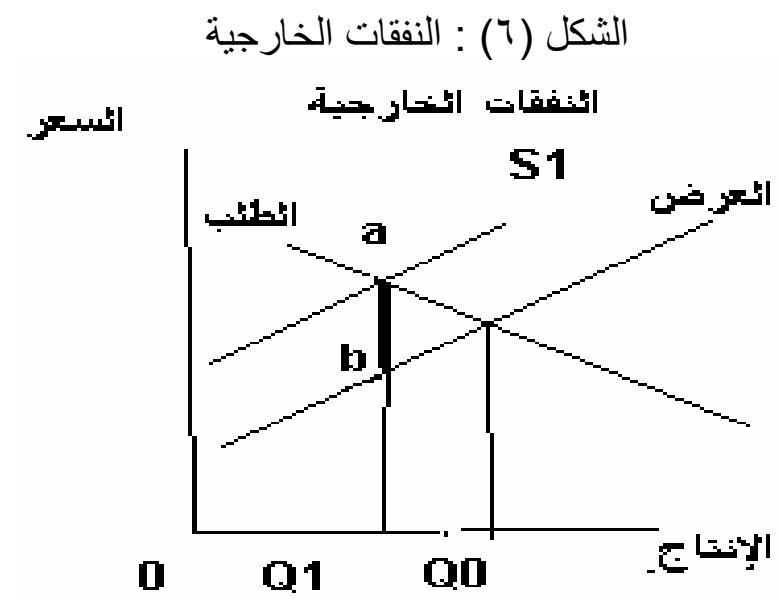

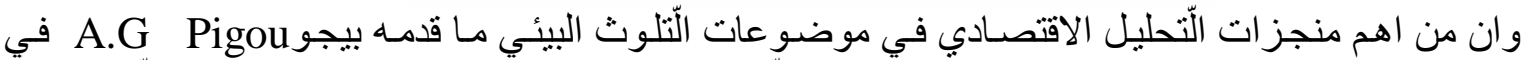

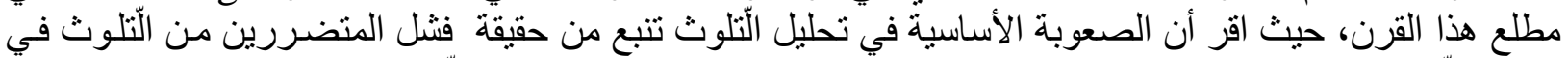

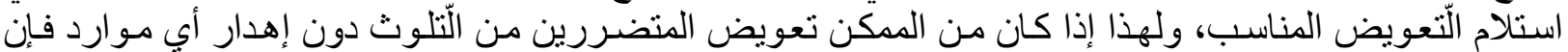

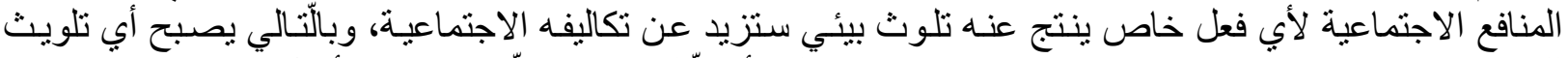

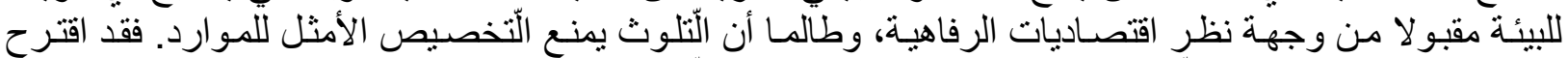

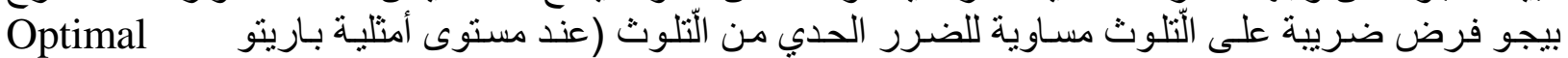

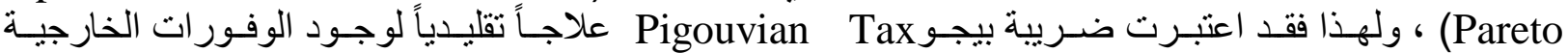

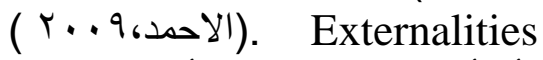

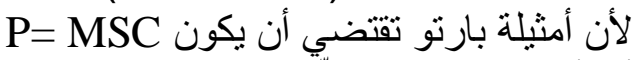

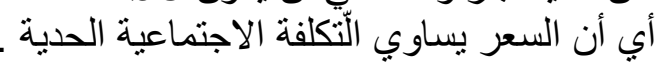

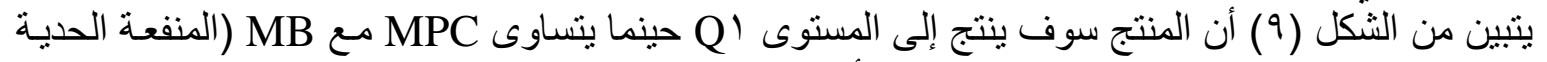

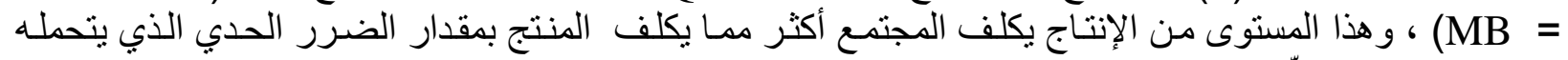
$\mathrm{MSC}=\mathrm{MPC}+\mathrm{MD}$

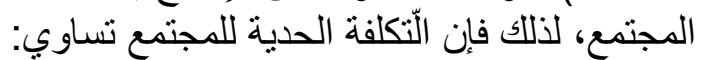

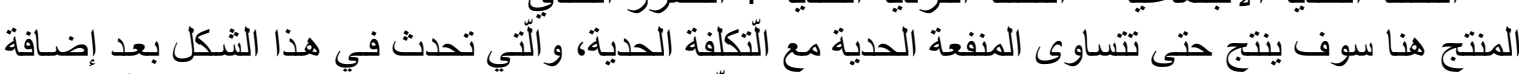

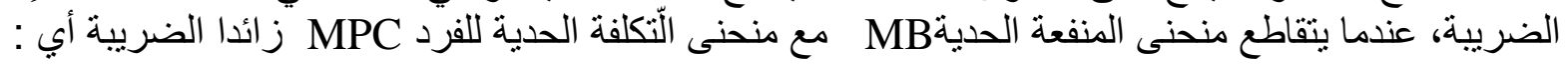
$\mathrm{MB} \mathrm{MB}=\mathrm{MPC}+\mathrm{t}$

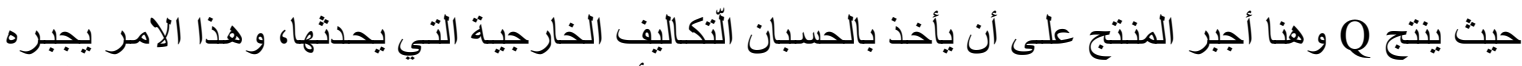

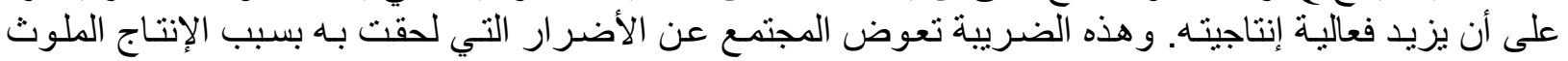




$$
\text { شكل (7) : اثز الضريبة على التلوث }
$$

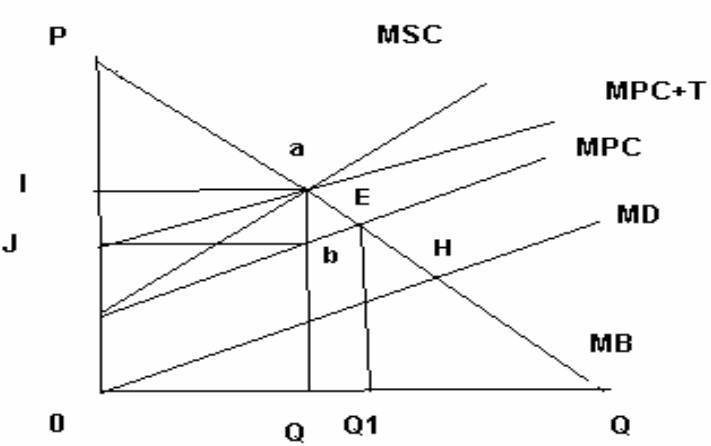

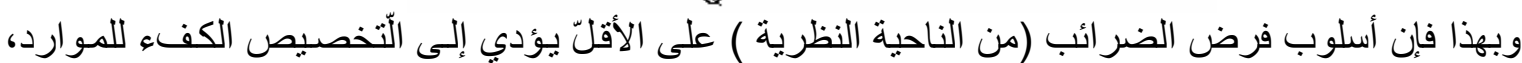

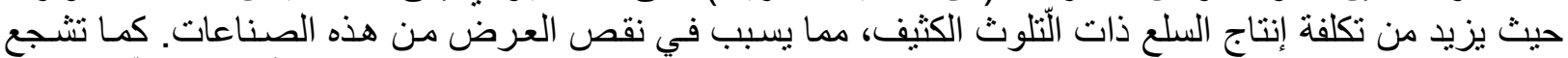

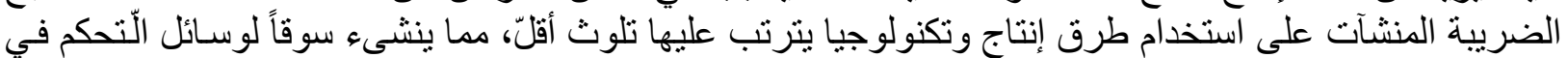

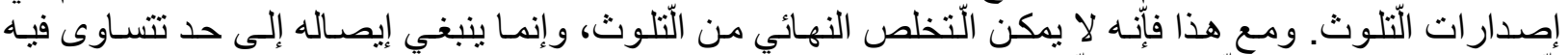

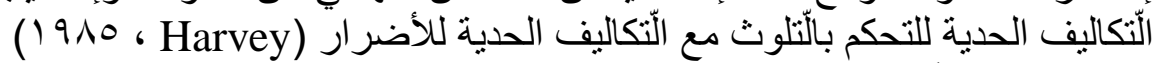

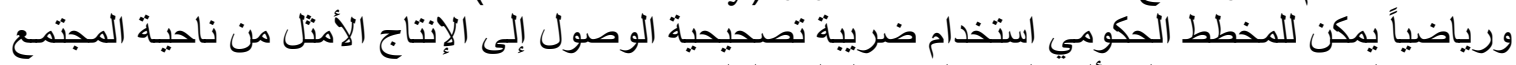
بعد إضافة الضريية تصبح المسألة بالنسبة لمنتج السلعة الملوثة المبة: $\pi=[(\operatorname{Max}(\mathrm{x})[\mathrm{PX}-\mathrm{C}(\mathrm{x})-\mathrm{t}(\mathrm{x})]$

$$
\mathrm{P}=\mathrm{C}^{\prime \prime}(\mathrm{x})+\mathrm{t}^{\prime \prime}(\mathrm{x})
$$$$
\text { ولحل x سيستوفي الثرط }
$$

و إذا ما تم وضع الضريبة بحيث ،

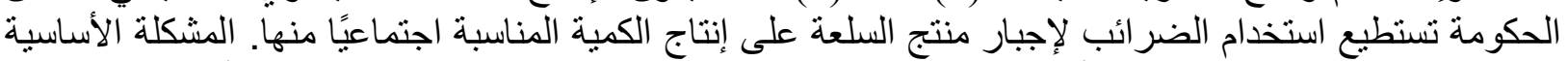

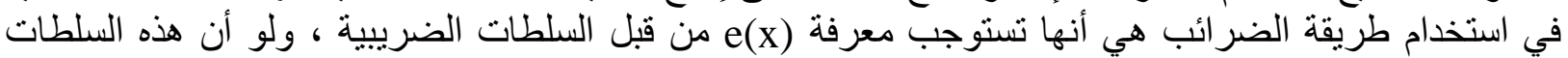
تعرف تللك المعلومة لاستطاعت تحديد الكمية (xe) التي يجب إنتاجها وفرضها على المنتج دون الحاجة إلى وضع ونع الضريية.

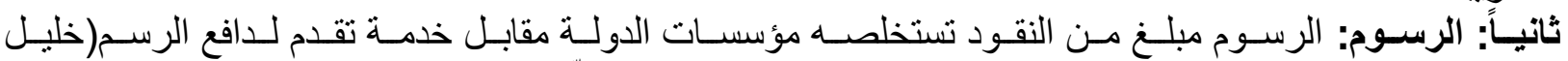

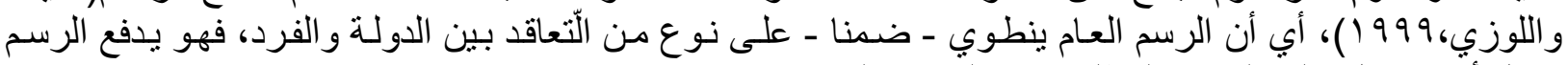

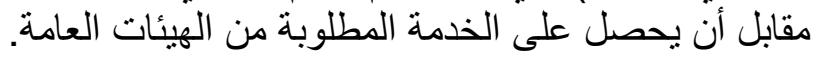

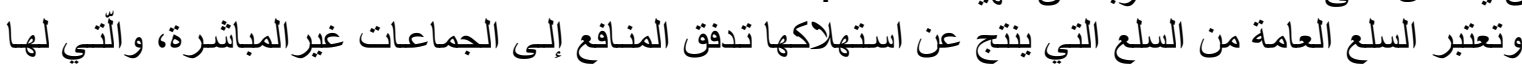
خاصيتان رئيسيتان:

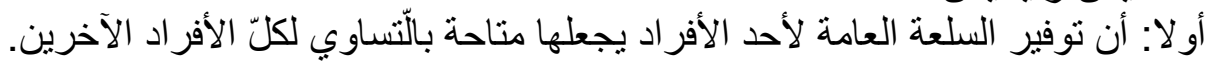

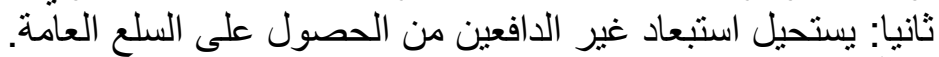

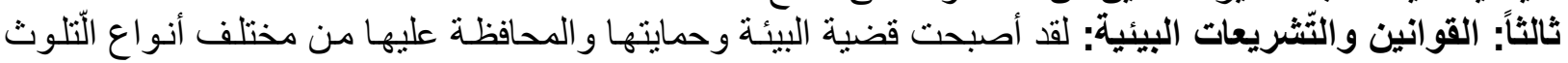

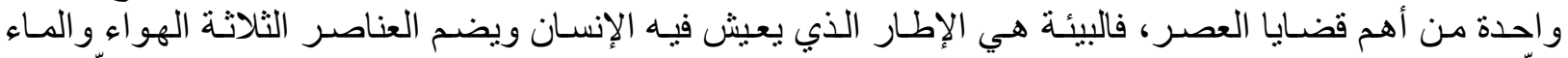

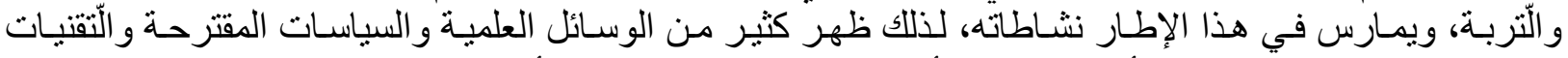

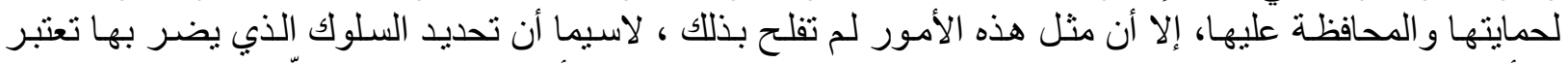

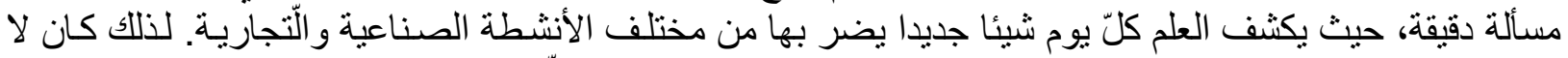

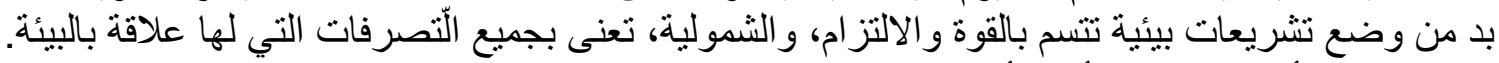

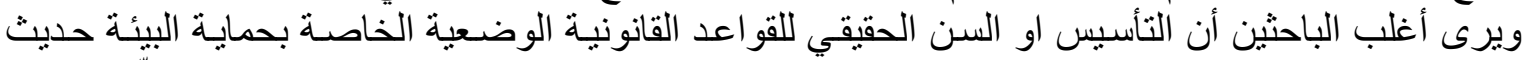

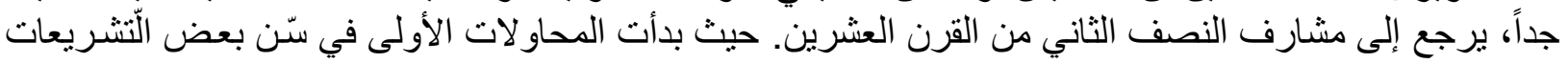

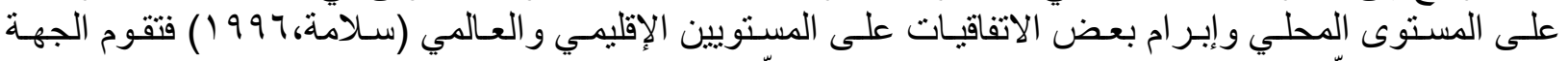

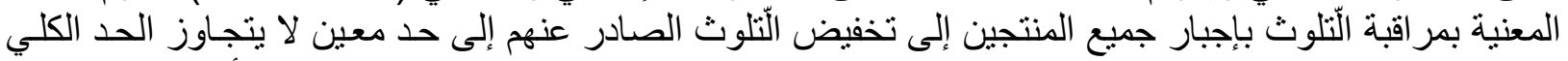

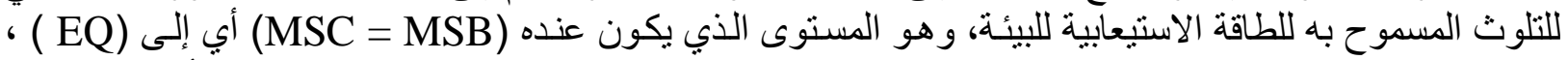

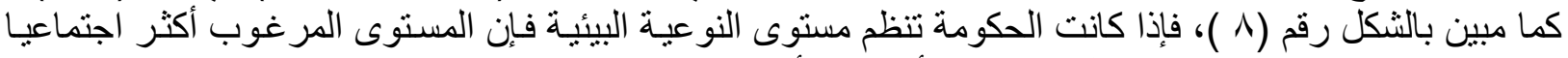

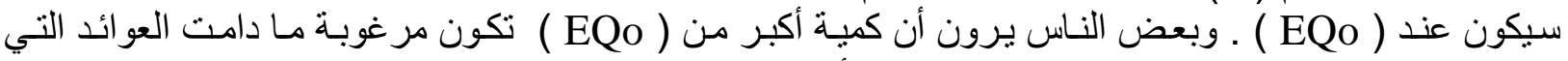

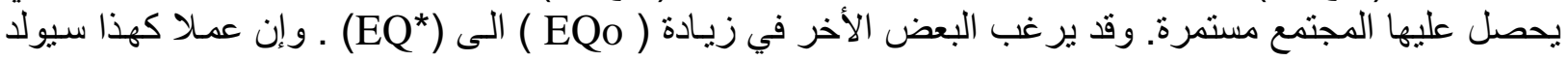




$$
\text { ～～ISSN: } \quad \text { ISS15-316X(Print) }
$$

مجلة زر اعة الر افدين

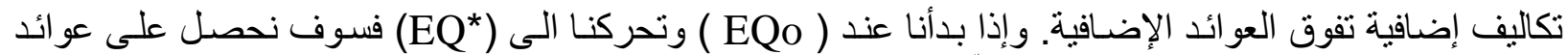

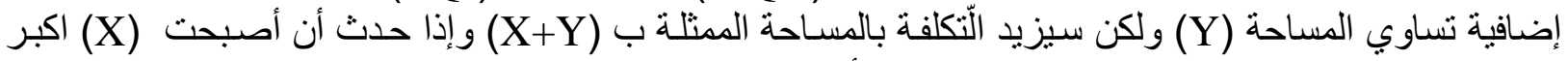

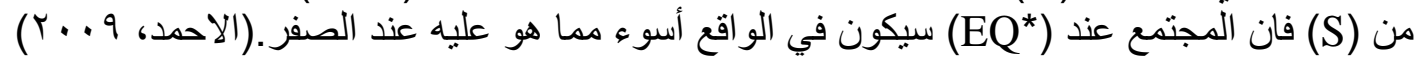

$$
\text { شكل (8) عو ائد المجتمع الصافية من النوعية البيئية المثالية }
$$

تعواند ائمجتميع ائصافية من انثوتية اليينية انمثالية

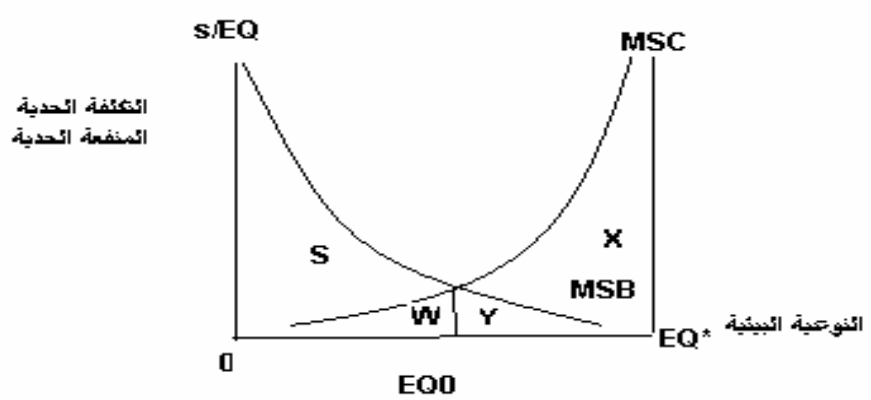

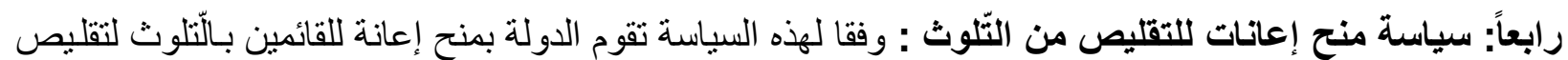

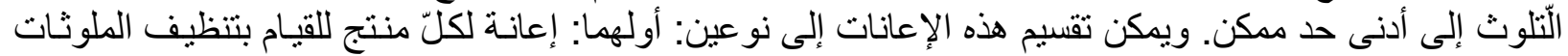

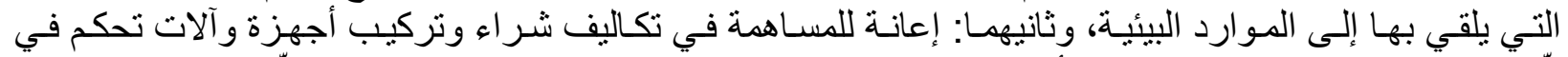

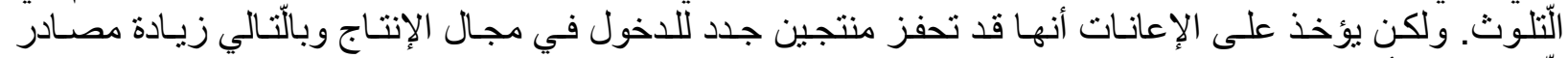

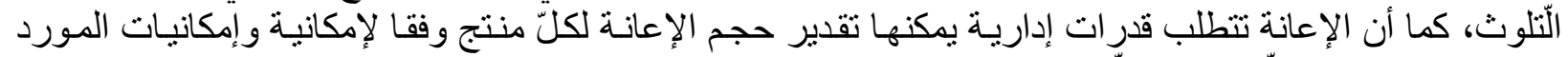

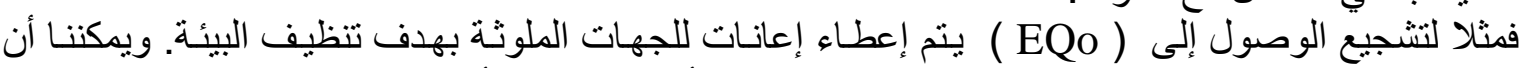

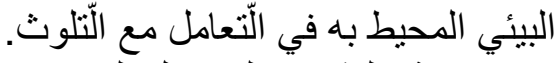

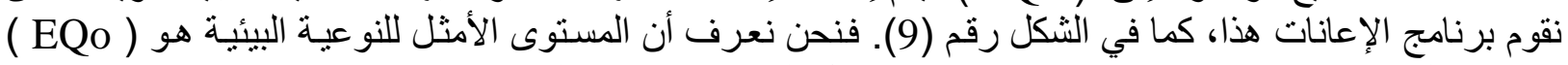

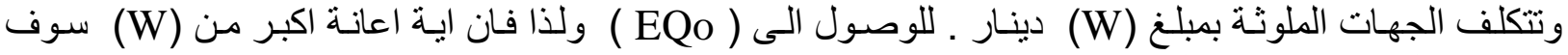

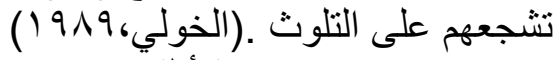

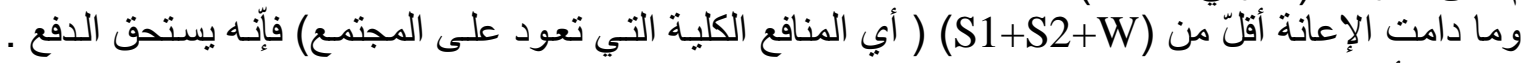

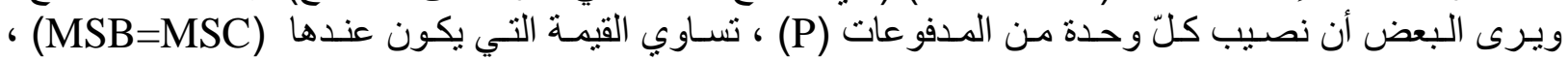
ويوفر ذلك عو ائد نقدية للملوث مقدار ها (S1+W) مقابل الحصول على ( EQo ) بتكلفة مقدارها (W) (W) . شكل (9) الحصول على النوعية البيئية المثلى عن طريق الاعانات

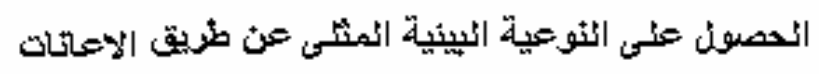

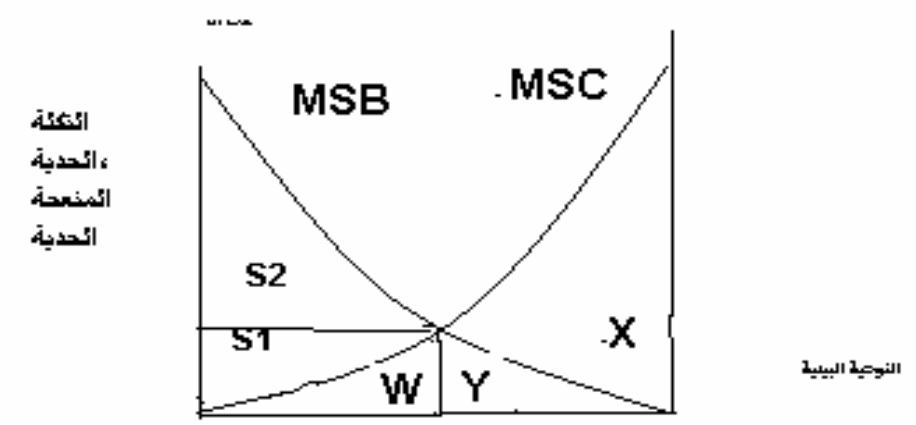

\section{$0 \quad E Q O \quad E Q^{*}$}

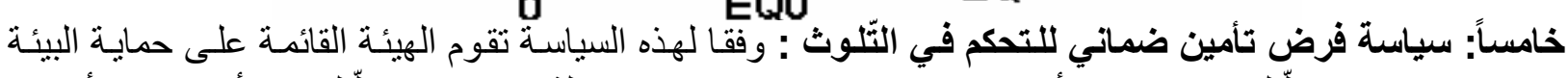

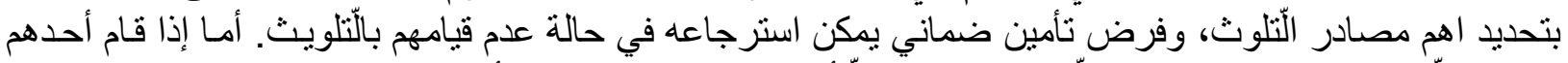

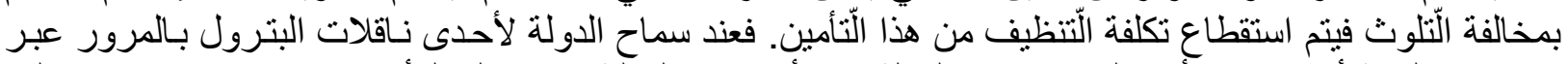

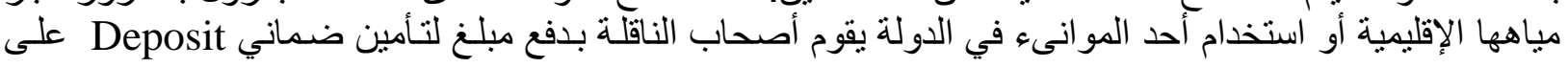




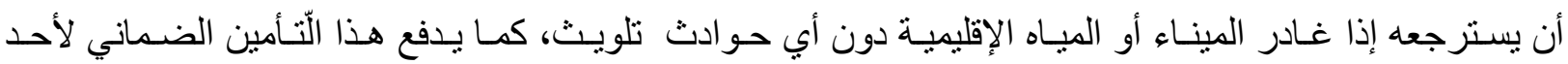

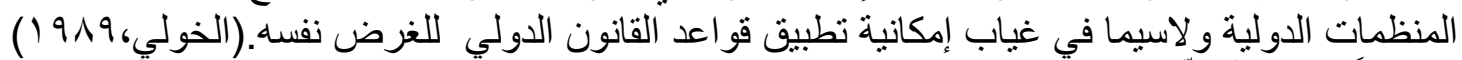

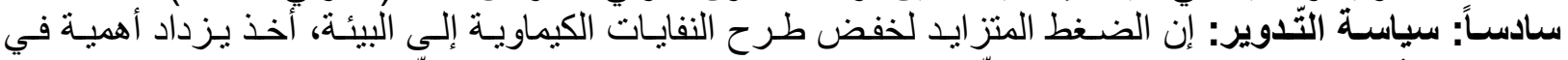

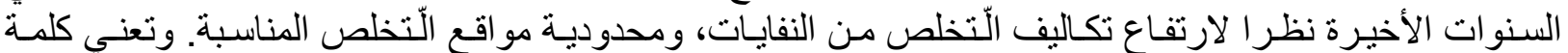

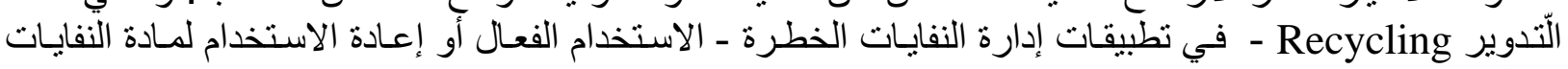
كبديل لمنتج تجاري.

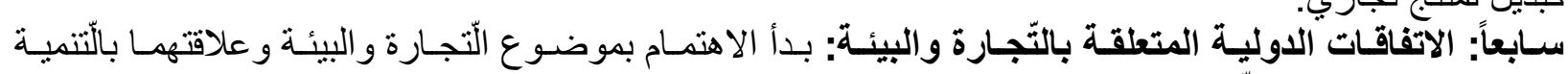

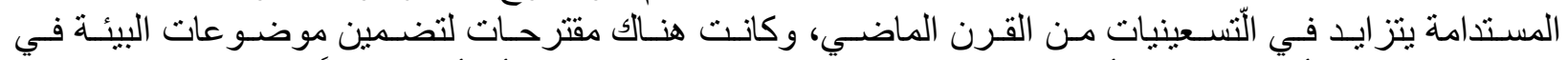

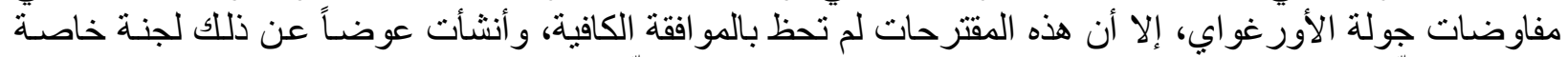

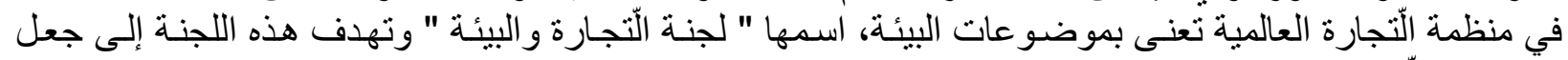

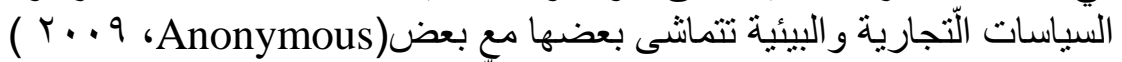

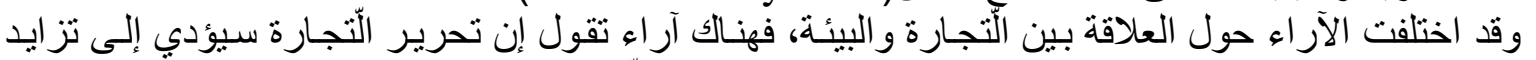

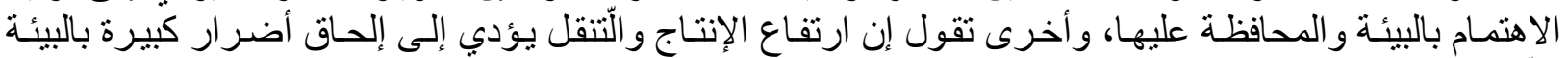
والتنمية المستديمة.

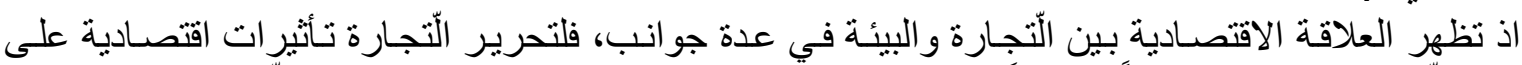

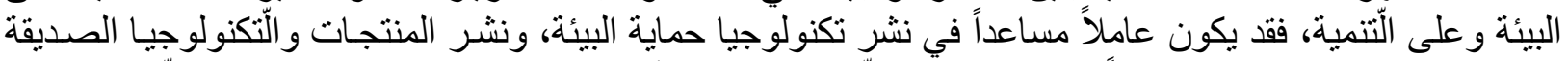

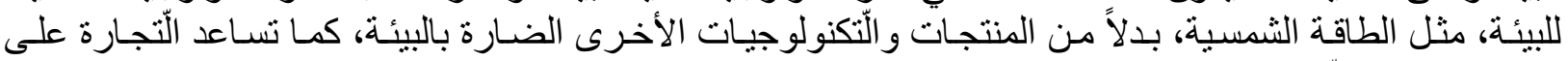

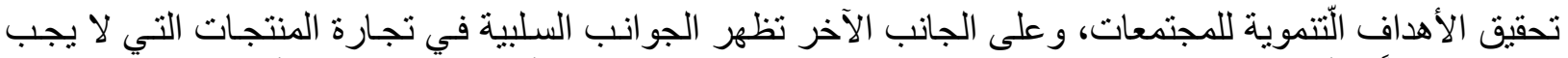

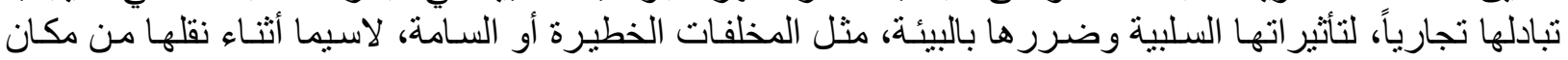

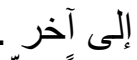
ثُامناً: التّربية البيئية: التّربية البيئية هي عملية تكوين القيم والاتجاهات و المهارت و المدركات اللازمـة لفهم وتقدير

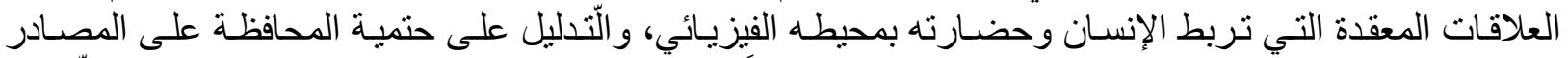

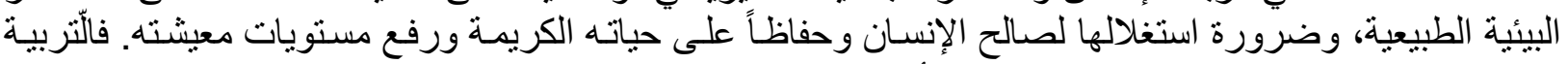

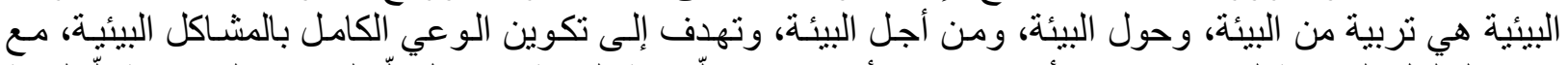

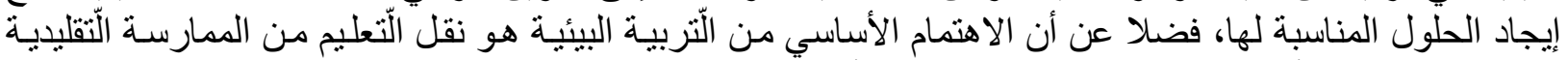

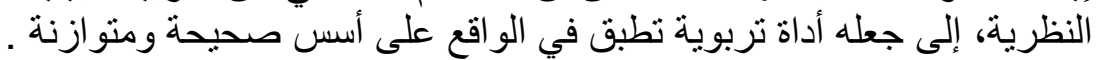

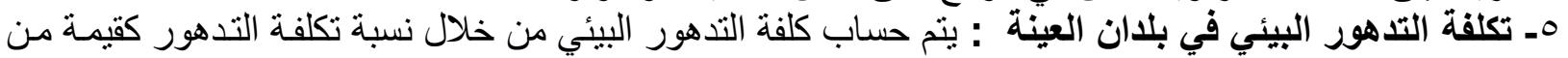

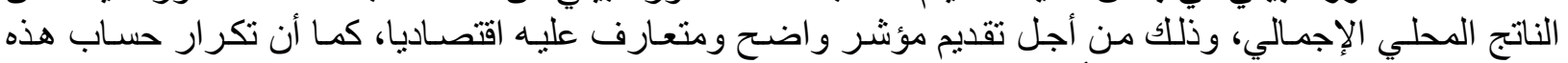

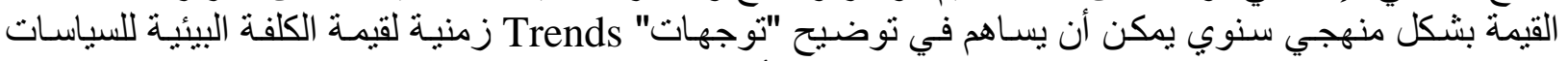

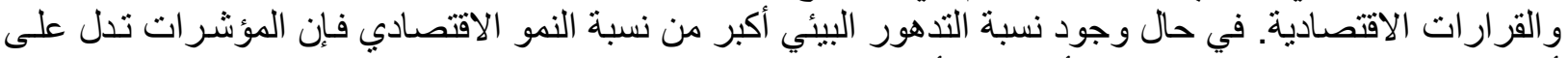

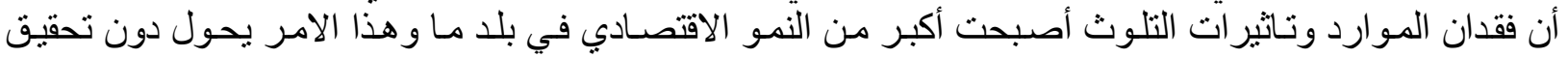

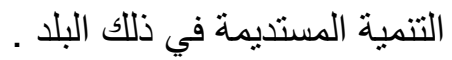

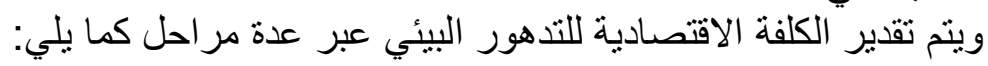

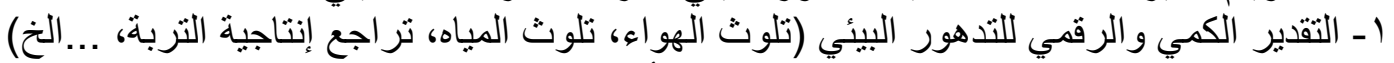

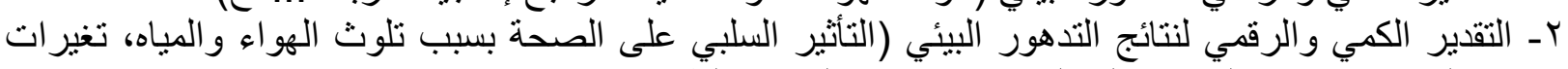

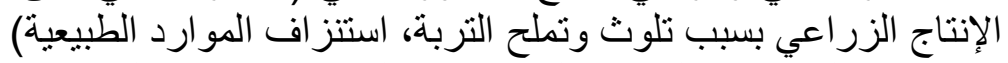

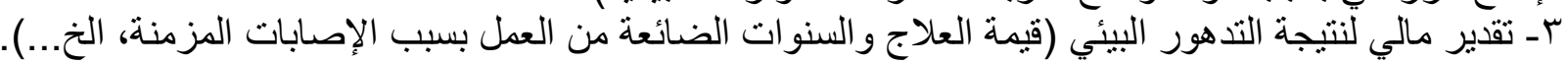

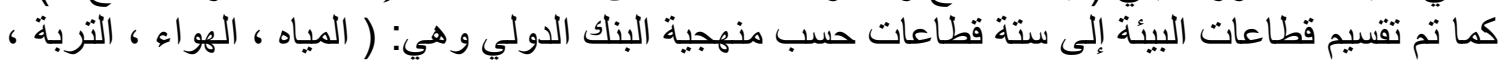

المخلفات والبيئة الساحلية وكذلك التأثير على البيئة العالمية وهو محدود تقريبا في بلدان العينة ).

\section{النتائج والمناقشة التئة}

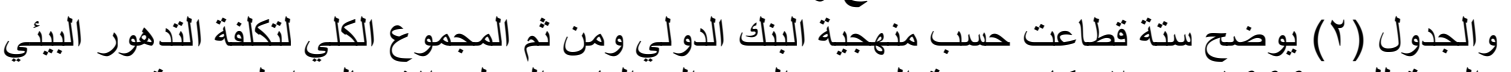

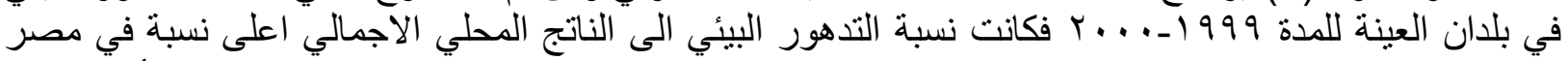

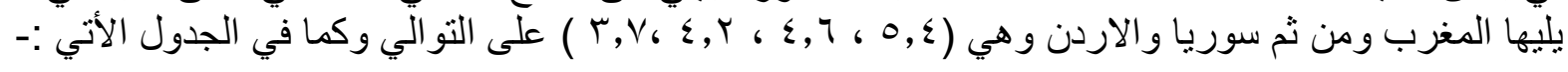


$\begin{aligned} \text { ISSN:2224-9796(Online) } & \text { ISSN: 1815-316X(Print) }\end{aligned}$

مجلة زر اعة الر افدين

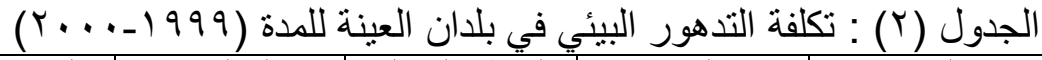

\begin{tabular}{|c|c|c|c|c|c|c|c|c|c|c|c|c|c|c|}
\hline \multirow{2}{*}{ الدراسة } & \multicolumn{2}{|c|}{ المجموع الكلي } & البيئة & \multicolumn{2}{|c|}{ المخلفات } & \multicolumn{2}{|c|}{ الدناطق الساحلية } & \multicolumn{2}{|c|}{ المياه } & \multicolumn{2}{|c|}{ الهواء } & \multicolumn{2}{|c|}{ الأرض } & \multirow[t]{2}{*}{ البلدان } \\
\hline & الإلي النسبة & مليون & موليارن & الإلنية الإلتج & دوليون & الإلناتجية & دوليون & الإلني & دوليون & الإلني & دوليور & الإلئية & موليور & \\
\hline r. & $r, v$ & $r, q$ & TYA & $\cdot, r$ & $1 \varepsilon$ & & & $\cdot, 7$ & 0. & $\cdot, \wedge$ & $\cdot, 7 \varepsilon$ & $1, r$ & 1.. & الأردن \\
\hline$r \cdots 1$ & $\varepsilon, Y$ & Nor & TYA & $\cdot, 1>$ & Ir & $\cdot, 1>$ & IT & $\cdot, \wedge$ & 104 & 1,1 & ris & 1,1 & $r \mu$. & سوريا \\
\hline r... & $0, \xi$ & $\varepsilon, \wedge \varepsilon$. & 07. & $\cdot, r$ & 11. & $\cdot, \Gamma$ & rq. & 1 & 14. & $1, r$ & 1.7. & $r, 1$ & $1, \wedge q$. & 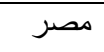 \\
\hline r... & $\varepsilon, \uparrow$ & $1,0 \%$. & $r \ldots$ & $\cdot, 0$ & 10. & $\cdot, 0$ & 17. & $\cdot, 0$ & IV. & $1, \cdot$ & $r \varepsilon$. & $1, Y$ & $\leqslant$ 1. & المغرب \\
\hline
\end{tabular}

المصدر البنك الدولي : تقدير التدهور البيئي في دول عربية مختلفة (1999 - ....

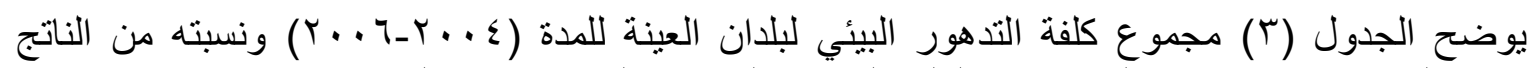

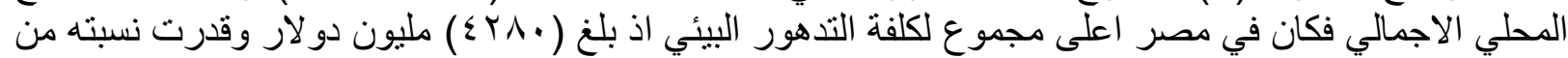

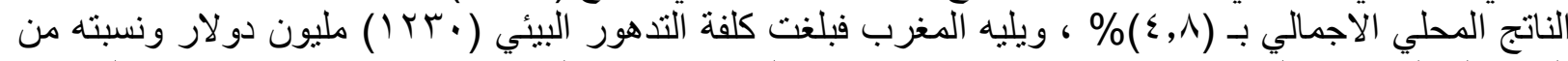

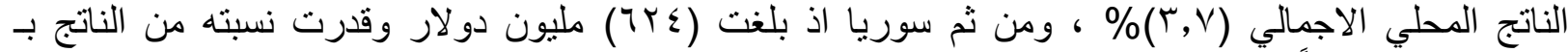

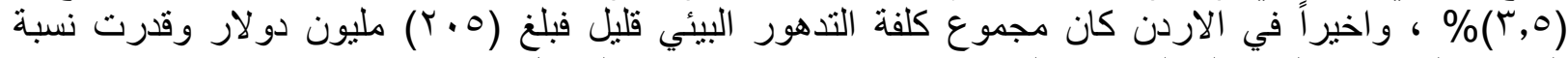

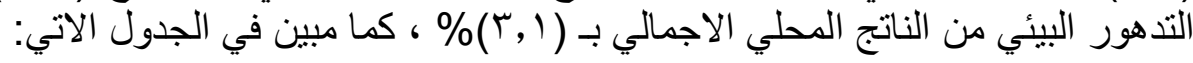

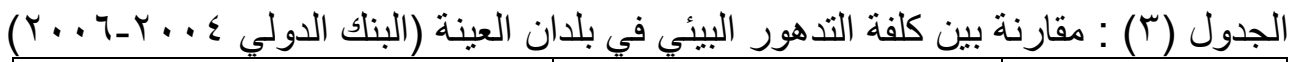

\begin{tabular}{|c|c|c|}
\hline من الناتج المحلي التدور البيئي & مجموع كلفة التدهور البيئي & البلدان البل \\
\hline$\% r, 1$ & Y.O & الأردن \\
\hline$\% \Gamma, 0$ & $7 Y \varepsilon$ & سوريا \\
\hline$\% \varepsilon, \wedge$ & $\Sigma Y \wedge$. & مصر \\
\hline$\% r, V$ & TKr. & المغرب \\
\hline
\end{tabular}

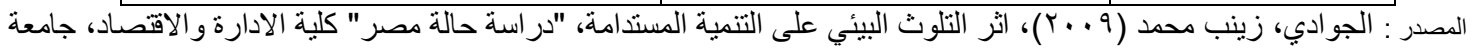
مصر اللعلوم و التكنولوجيا زين.

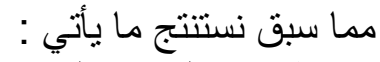

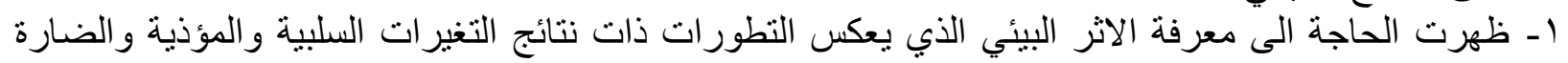
و هو ماتسعى البلدان الى تحديده وقياسه لمعرفة حجم الاثار والاضرار الاقتصادية والبيئية والاجتماعية والصية الصحية

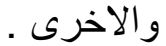
ب- ظهرت الحاجة الى تقييم الاثر البيئي لكل المشاريع المزمع قيامها لتقويم وتقدير تكاليف الخسائر والاضرار

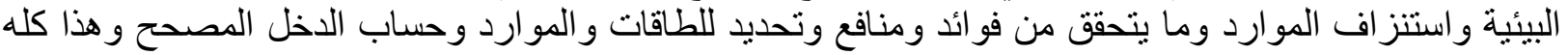

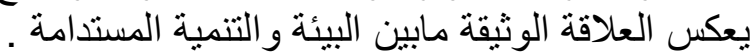

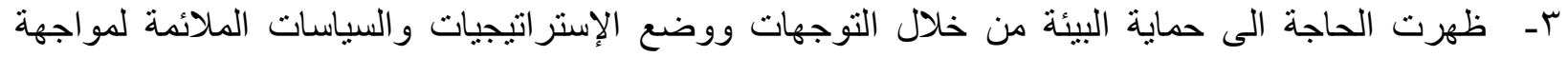

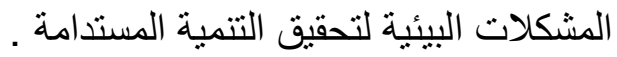

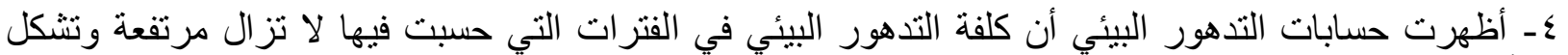

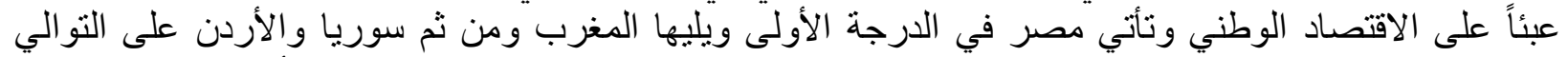

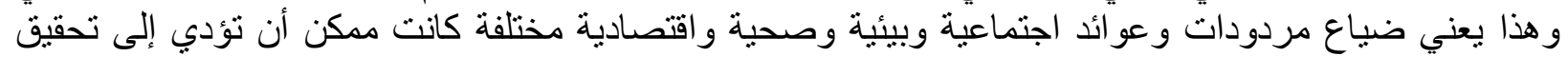

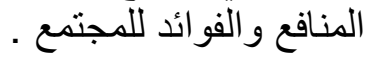

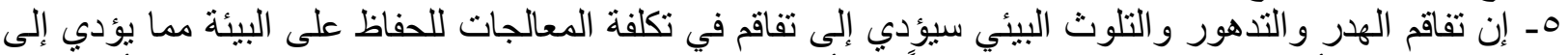

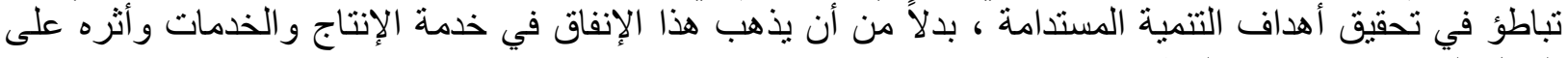

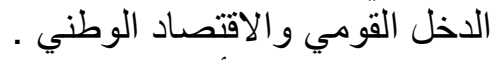
و عليه نوصي بما يأتي : 


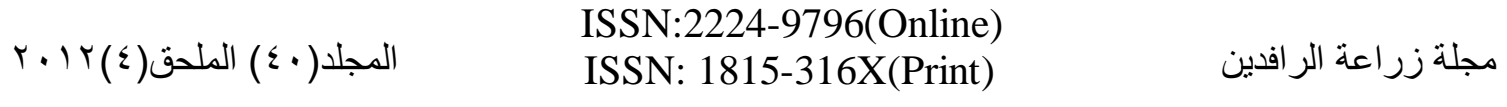

ا ـ الاهتمام باقتصاديات البيئة وحساب الاثر البيئي و الكلفة والعائد .

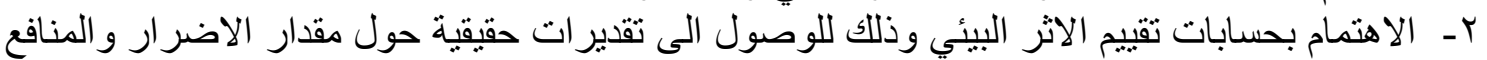

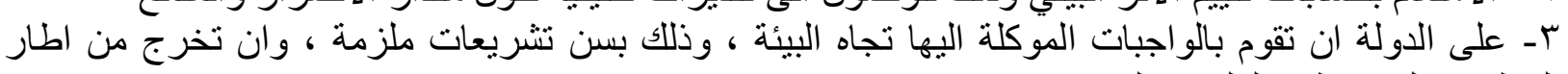
التنظير ، الى الاطار العلمي و التنفيذي .

\title{
ECONOMICS OF THE ENVIRONMENT AND THE EXPENSE OF ENVIRONMENTAL DEGRADATION IN SELECTED ARAB COUNTRIES FOR THE PERIOD 1999-2006
}

\author{
Salim Mohammed Salih Al-Youzbaki Naseem Zuhair Hamad Abdullah \\ Agricultural Economy Dept., College of Agricultural and Forestry, \\ Mosul University. Iraq \\ naseem.zuhair@yahoo.com_salim51956@yahoo.com
}

\begin{abstract}
The study aims to identify of the economics of the environmental and their effects on of the reality resources and the nature economic development, and to the expense of environmental degradation in the sample countries using style descriptive, and because of what ails the environmental today of the problems and damage aggravated dangerous and threatening annihilation of all living organisms, including humans, and for that loud trends, and fell a part pens and held international meetings and organizations formed and research environmental centers and made a lot of legislation to put an end to this environmental degradation, Warner dangers expected of the land and threatened with extinction for all living organisms, including humans, as it is no longer comprehend the environment5al issue of the welfare and conditions for the life of an optimal. But an important issue in human life beyond its economic, social and education of the population, this researcher concluded that the cost of environmental degradation in the periods in which calculated which is still high and constitute a burden on the national economy and Egypt comes primarily, followed by Morocco and then Syria and Jordon, respectively this means the loss of social and environmental returns, health, health and economic result was different was possible that lead to the realization of benefits and the benefits to the community.
\end{abstract}

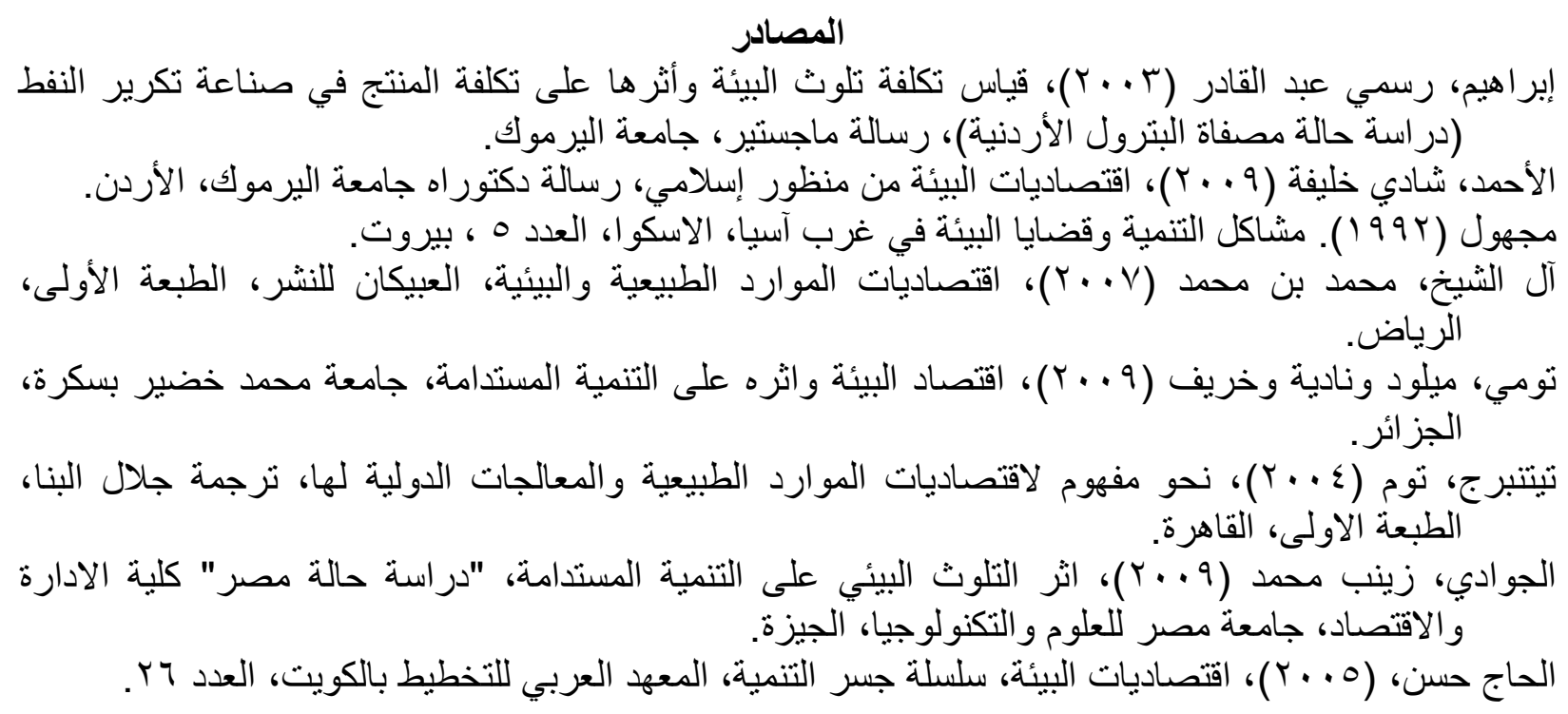




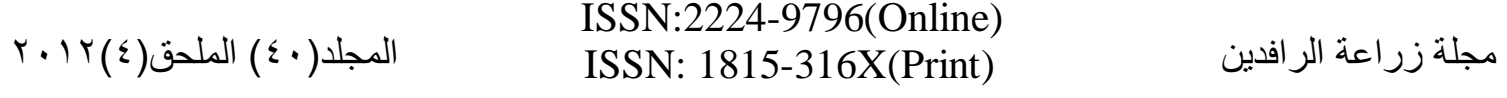

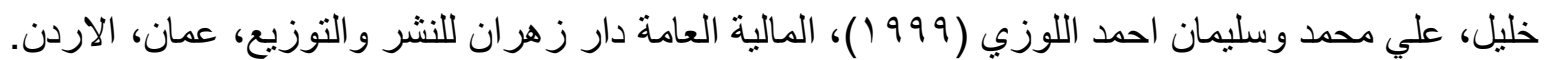

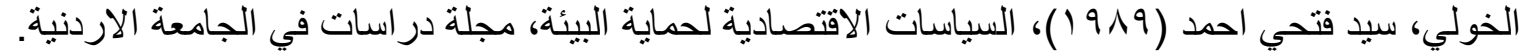

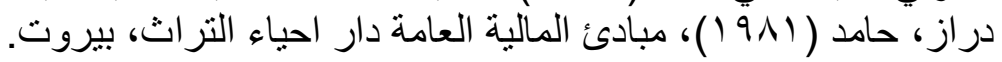

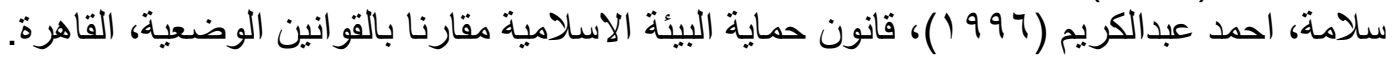

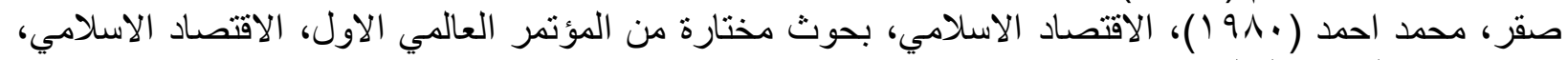

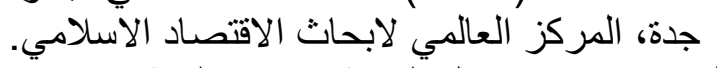

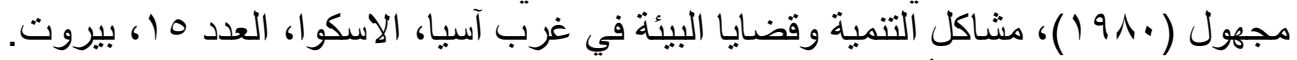

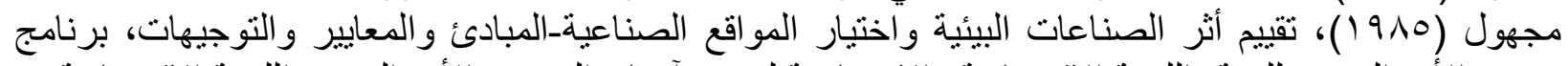

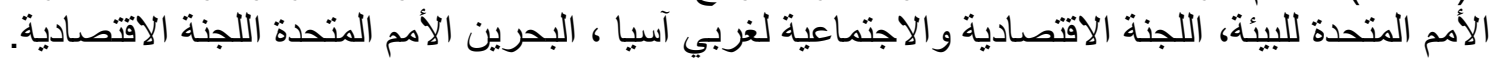

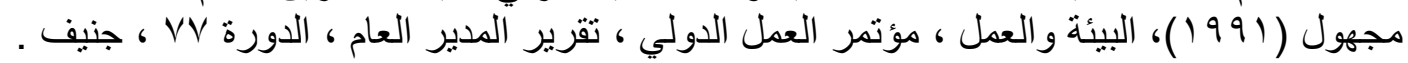

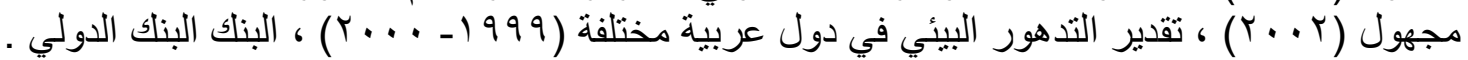

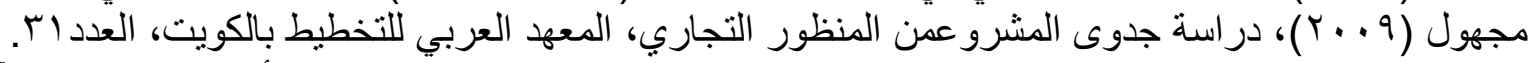

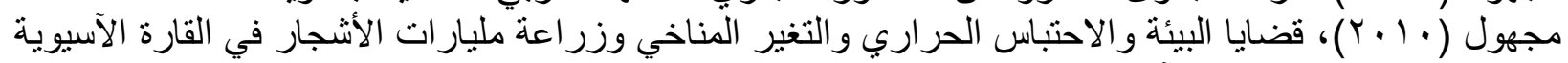

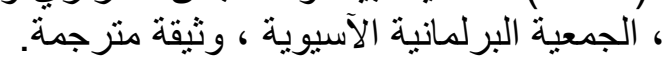

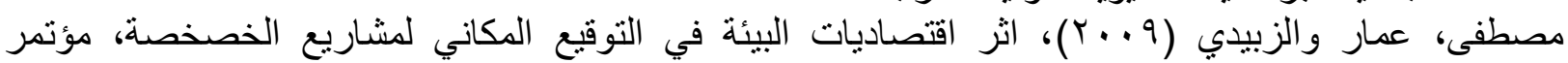

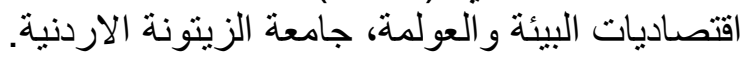

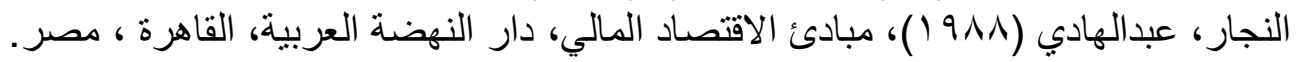
Anonymous (2009), Report On Environment and Development, Sida, April . Harvey S. Rosen (1985), public Finance; Irwin Homewood, Illinois.

James, D and B. Boer, (1988), Application Of Economic Technique In Environmental Impact Assessment, Preliminary Report, Macquarie University, Australia.

Torras , M. and J. Boyce,(1998), Income, inquality, andpollution:a reassessment of the environmental Kuznets curve, Ecological Economics , 25, (2). 